\title{
Uncertainty analysis of adsorption measurements using commercial gravimetric sorption analyzers with simultaneous density measurement based on a magnetic-suspension balance
}

\author{
Xiaoxian Yang $^{1}$ (D) $\cdot$ Reiner Kleinrahm $^{2} \cdot$ Mark O. McLinden $^{3} \mathbb{D} \cdot$ Markus Richter $^{1,4} \mathbb{D}$
}

Received: 19 July 2019 / Revised: 17 January 2020 / Accepted: 7 April 2020 / Published online: 27 April 2020

(c) The Author(s) 2020

\begin{abstract}
A commercial gravimetric sorption analyzer, which is based on a magnetic-suspension balance, was significantly improved to reduce the uncertainty in adsorption measurements. In a previous paper, we investigated the force-transmission error (FTE) of the instrument's magnetic-suspension coupling, and we analysed the uncertainty of the density measurement. In the present paper, equations for the determination of the adsorption on porous and quasi non-porous materials are provided, where the FTE is taken into account, and a detailed uncertainty analysis is presented. The uncertainty analysis was applied to both the improved measurement system and a typical commercial gravimetric sorption analyzer. Adsorption test measurements were conducted with carbon dioxide along the $T=283 \mathrm{~K}$ isotherm at pressures up to the dew-point pressure using both a porous material (zeolite 13X) and a quasi non-porous material (solid metallic sinkers). The major uncertainty contributions for adsorption on the porous material were the mass and volume of the adsorbent sample and the assumption of the density of the adsorbed fluid; for the quasi non-porous material, the main contributions were the weighing values of the balance, the density of the investigated fluid in the gas phase, and the volume of the non-porous material. The influence of the FTE on the adsorption on the porous material was approximately $0.002 \mathrm{mmol} \cdot \mathrm{g}^{-1}$, which was negligibly small; but the influence of the FTE was significant in the case of the quasi non-porous material, i.e., approximately $0.7 \mathrm{mmol} \cdot \mathrm{m}^{-2}$ or about $22 \%$ of the adsorption capacity with the highest adsorption observed in this work (near the dew-point pressure). This indicates that the influence of the FTE increases significantly with decreasing adsorption capacity of the adsorbent sample.
\end{abstract}

Keywords Adsorption isotherm · Gravimetric sorption analyzer · Magnetic-suspension coupling · Tandem-sinker densimeter · Uncertainty analysis

\section{Introduction}

Gas adsorption and desorption naturally occur in various physical, chemical and biological systems. Technologies based on sorption are widely applied in industries

Markus Richter

m.richter@mb.tu-chemnitz.de

1 Fluid Science \& Resources Division, The University of Western Australia, Crawley, WA 6009, Australia

2 Thermodynamics, Ruhr University Bochum, Bochum 44780, Germany

3 Applied Chemicals and Materials Division, National Institute of Standards and Technology, Boulder, CO 80305, USA

4 Applied Thermodynamics, Chemnitz University of Technology, Chemnitz 09107, Germany utilizing porous materials like activated carbon, silica gels, metal-organic frameworks, zeolites and many more. Isothermal adsorption measurements of gases on porous materials provide fundamental information for the system design in industrial applications. However, the results of the adsorption measurements of the same gas on the same type of porous material performed by different research groups often show large deviations. For example, Fig. 1 shows the adsorption measurements of carbon dioxide on zeolite $13 \mathrm{X}$ along the $T=323.15 \mathrm{~K}$ isotherm of four different groups (Wang and LeVan 2009; Cavenati et al. 2004; Hyun and Danner 1982; and Deng et al. 2012); their differences are very large. An inter-laboratory study (Zlotea et al. 2009) carried out to evaluate the hydrogen sorption properties of a commercial microporous carbon material showed that the dispersion of isotherms measured by fourteen laboratories increased with pressure with relative deviations up to $36 \%$. 




Fig. 1 Results of adsorption measurements of carbon dioxide on zeolite $13 \mathrm{X}$ at $T=323.15 \mathrm{~K}$, conducted by four different research groups: +, Wang and LeVan 2009; ×, Cavenati et al. 2004; O, Hyun and Danner 1982; $\square$, Deng et al. 2012. The large deviations among the four data sets are briefly discussed in Sect. 1

Such large deviations have been commonly realized, and there is increasing research to investigate the reasons and to standardize gas-solid sorption measurements. Kaye et al. (2007) reported that the gas adsorption capacity was significantly affected by the preparation and handling methods of the porous samples, e.g., the differences in the reaction temperature and reaction time (please note: the term "reaction" as stated by Kaye et al. (2007) refers most likely to "regeneration"). Broom and Webb (2017) discussed the potential pitfalls encountered in hydrogen sorption measurement; the pitfalls were grouped into issues associated with instrument design and calibration, sample size, sample and gas purity, isotherm measurement procedure, achievement of equilibrium, and data analysis. Gensterblum et al. (2009) reported the measurement results of an inter-laboratory study among four European research laboratories and showed that when thorough optimization of instrumentation and measurement as well as proper sample preparation procedures were applied, the carbon dioxide sorption on Filtrasorb 400 activated carbon in the supercritical range could be determined accurately with both gravimetric and volumetric instruments. Nguyen et al. (2018) reported the results of an international inter-laboratory study led by the National Institute of Standards and Technology on the measurements of high-pressure excess carbon dioxide sorption isotherms on a reference material (ammonium ZSM-5 zeolite) and provided recommendations for optimising the acquisition of physisorption isotherm data including activation procedures, data processing methods to determine adsorption uptake and the appropriate equation of state (EOS) to be used.

There is no doubt that accurate measurement techniques, strict experimental procedures, deep understanding of the measurement uncertainty, and data analysis methods based on the interdisciplinary knowledge of sorption science and thermophysical properties are of paramout importance in providing reliable adsorption data. The question is how much exactly the large deviation among different researchers results from the measurements and the methods of data analysis? There are various techniques in measuring adsorption isotherms, e.g., by the use of a volumetric adsorption equilibrium apparatus (e.g., Wang and LeVan 2009) or a gravimetric sorption analyzer incorporating a magneticsuspension balance (e.g., Cavenati et al. 2004). In the present work, we focus on the latter one, and with a detailed uncertainty analysis, we try to answer this question regarding a gravimetric sorption analyzer. Although an uncertainty analysis of a gravimetric sorption analyzer has been presented in the literature (e.g., Ottiger et al. 2008), here, we also include the analysis of the force-transmission error (FTE, see Sect. 3.1) and the analysis for the measurements of nonporous materials in this work.

The usual type of a gravimetric sorption analyzer (see Sect. 2) has been widely used for sorption measurements (e.g., Dreisbach and Lösch 2000; May et al. 2001; Cavenati et al. 2004; and Hefti et al 2015). In our previous work (Kleinrahm et al. 2019), a commercial gravimetric sorption analyzer was significantly improved to reduce the measurement uncertainty. Moreover, the FTE of the magneticsuspension coupling was systematically investigated, and the uncertainty of the density measurement was analysed in detail. In the present work, equations for the determination of the adsorption on porous and non-porous materials are provided, where the FTE is taken into account. Furthermore, a detailed uncertainty analysis is presented. The improved measurement system was used to conduct adsorption measurements of carbon dioxide on zeolite 13X (porous material) and on solid metallic sinkers (quasi non-porous material) along the isotherm at $T=283 \mathrm{~K}$ up to the dew-point pressure. The uncertainty analysis was applied to both the improved measurement system now available at Chemnitz University of Technology and to a hypothetical typical commercial gravimetric sorption analyzer.

\section{Apparatus description}

\subsection{Measurement principle}

A gravimetric sorption analyzer incorporating a magneticsuspension balance was first developed by Dreisbach and Lösch in the late 1990s and published by them in 2000. It was designed to measure the adsorption of a sample gas on a porous material and, by the use of a "density sinker", to simultaneously measure the density of the sample gas surrounding the porous material. Such an instrument has been commercially available from Rubotherm, Germany, since 
Fig. 2 Schematic representation of the three weighing positions of a typical commercial gravimetric sorption analyzer. ZP: zero position or tare position, where only the permanent magnet with the lifting rod assembly is in suspension; MP1: measuring position 1 , where the sample container with its lifting rod and the porous sample inside are lifted; MP2: measuring position 2 , where the density sinker at the top position is lifted into suspension as well

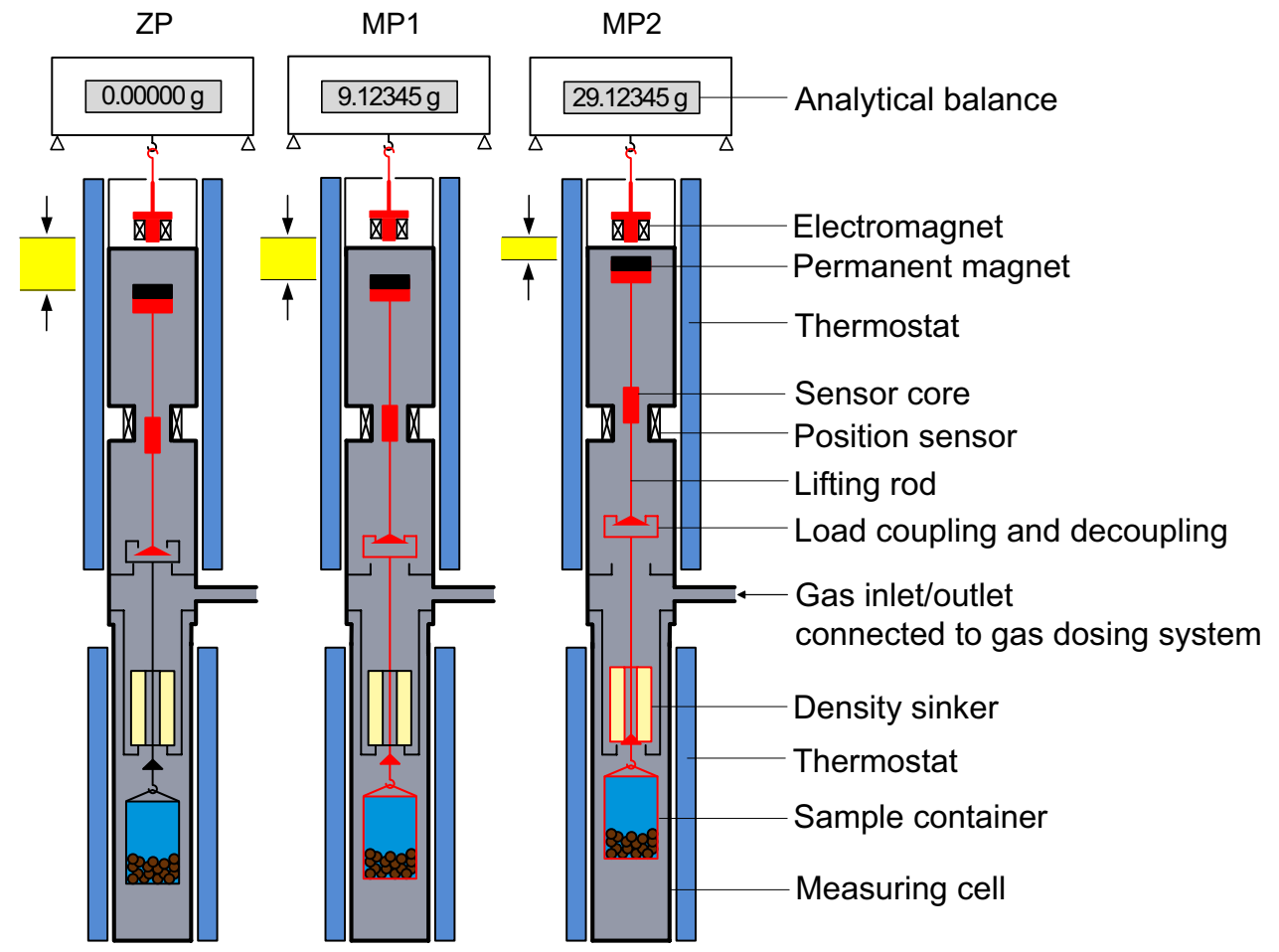

1999 (since 2016, the company is a part of TA Instruments, USA). ${ }^{1}$ The principle of a gravimetric sorption analyzer is illustrated in Fig. 2. The core apparatus is normally accommodated in a frame with an analytical balance at the top, a magnetic-suspension coupling underneath and a measuring cell at the bottom. The balance is placed under ambient conditions, while both the magnetic-suspension coupling and the measuring cell are thermostated with an external circulating bath. The measuring cell is connected to a gasdosing system, which is used to control the pressure inside the measuring cell.

The magnetic-suspension coupling is the key component of a gravimetric sorption analyzer to be used over large temperature and pressure ranges. It comprises (1) an electromagnet that is hung from the weighing hook of the balance, (2) a permanent magnet together with a lifting rod, which are together levitated by the electromagnet, and (3) a position sensor as well as a feedback control circuit that makes fine adjustments in the electromagnet current to maintain the permanent magnet in different stable suspension positions. The change in the height of the permanent magnet yields three stable positions: (1) a tare or zero position (ZP), where only the permanent magnet together with the lifting rod assembly

\footnotetext{
${ }^{1}$ Certain trade names and products are given to adequately document the experimental equipment and procedures. This does not constitute a recommendation or endorsement of these products by the National Institute of Standards and Technology, nor does it imply that the products are necessarily the best available for the purpose.
}

is freely levitated, (2) a lower measuring position 1 (MP1), where the adsorbent (sample container with its lifting rod and the porous material inside) at the bottom position is lifted, and (3) an upper measuring position 2 (MP2), where both the adsorbent at the bottom position and the density sinker at the top position are picked up. The density sinker, as it is named, is used for the determination of the density of the sample gas. By using the magnetic-suspension coupling, the load of the density sinker and the adsorbent in the pressurized measuring cell are transmitted to the balance (through the pressure-proof wall of the measuring cell) without direct contact. Based on the difference in the weighing values in positions MP1 and MP2, the density of the fluid in the measuring cell can be calculated (see Sect. 3.1), and based on the difference in the weighing values in positions $\mathrm{ZP}$ and MP1, the adsorption on the adsorbent can be calculated (see Sect. 3.2).

\subsection{Improved measurement system}

In our previous work (Kleinrahm et al. 2019), we took a gravimetric sorption analyzer and improved it to obtain a significantly lower measurement uncertainty; it was essentially turned into a tandem-sinker densimeter, as we named it in that work. A schematic diagram of the tandem-sinker densimeter is illustrated in Fig. 3. The key modification was the reversible replacement of the sample container at the bottom position to a solid sinker, which has a relatively large surface-to-volume ratio and is named "sorption sinker" here 
Fig. 3 Schematic representation of the three weighing positions of a tandem-sinker densimeter. ZP: zero position or tare position, where only the permanent magnet and the lifting rod assembly is in suspension; MP1: measuring position 1, where sinker 1 is lifted; MP2: measuring position 2 , where both sinkers are lifted into suspension
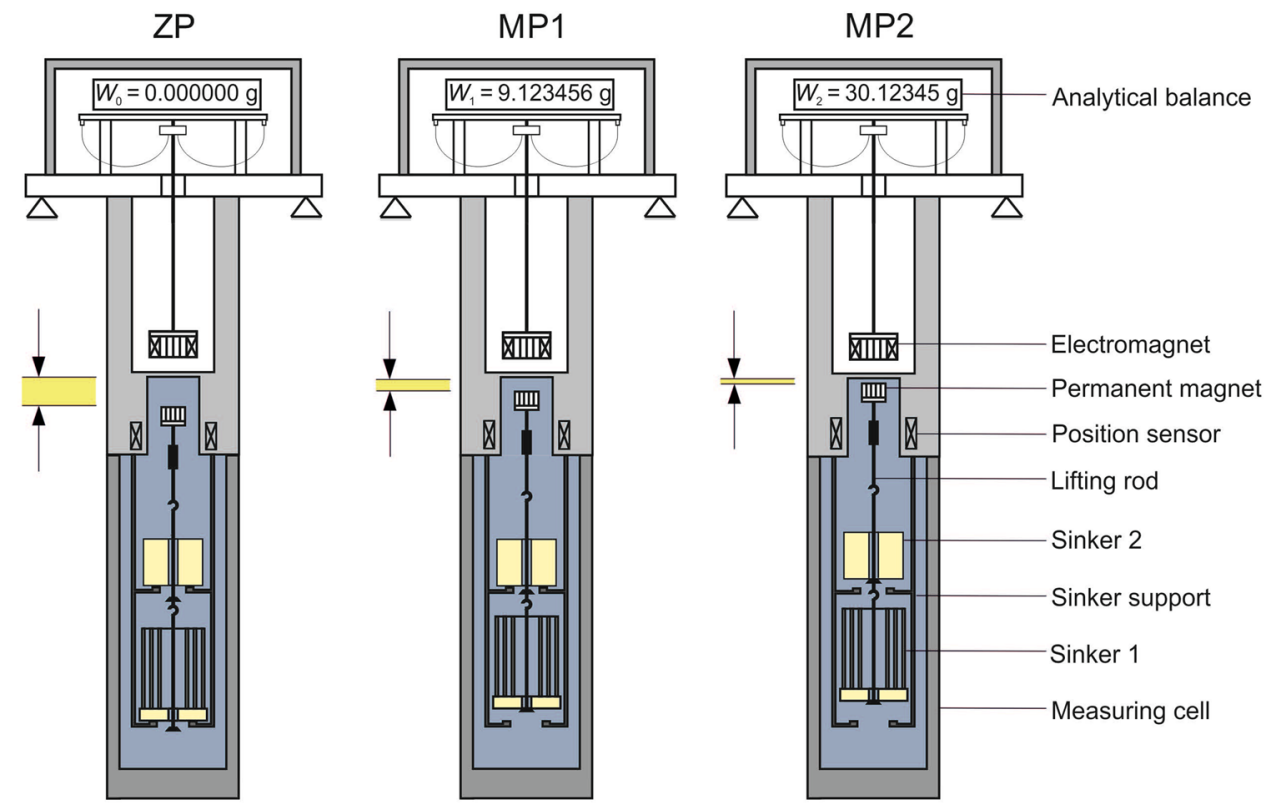

\begin{tabular}{llllllll}
\hline Sinker & Material & $m / \mathrm{g}$ & $10^{6} U(\mathrm{~m}) / \mathrm{m}$ & $V_{0} / \mathrm{cm}^{3}$ & $10^{6} U\left(V_{0}\right) / V_{0}$ & $A / \mathrm{cm}^{2}$ & $U(A) / A$ \\
\hline Ti20 $^{\mathrm{a}}$ & Titanium & 19.65711 & 20 & 4.360347 & 10 & 18.1 & 0.02 \\
SS09 $^{\mathrm{b}}$ & SS304 $^{\mathrm{c}}$ & 9.33899 & 60 & 1.17931 & 200 & 89.2 & 0.02 \\
\hline
\end{tabular}

The mass and volume of the Ti20 sinker (density sinker) were determined at NIST, while the mass and volume of the sinker SS09 (sorption sinker) were determined at Ruhr University Bochum. $U(m) / m, U\left(V_{0}\right) / V_{0}$ and $U(A) / A$ are the relative expanded uncertainty $(k=2)$ of the mass, volume and geometrical surface area, respectively. $V_{0}$ is the volume of the sinker at reference state $\left(p_{0}=0.101325 \mathrm{MPa}\right.$ and $\left.T_{0}=293.15 \mathrm{~K}\right)$

${ }^{a}$ The density sinker is a cylinder with outer diameter $d_{\mathrm{o}}=18.2 \mathrm{~mm}$, concentric inner diameter $d_{\mathrm{i}}=5.0 \mathrm{~mm}$, and height $h=18.2 \mathrm{~mm}$; surface polished with abrasive to obtain a smoother finish

${ }^{\mathrm{b}}$ Sorption sinker with a base ring $d_{\mathrm{o}}=20.0 \mathrm{~mm}, d_{\mathrm{i}}=5.0 \mathrm{~mm}, h=6.0 \mathrm{~mm}$, and three upper rings: thickness $0.1 \mathrm{~mm}, d_{\mathrm{o}}=(11.0,15.0,19.0) \mathrm{mm}$, and $h=27.0 \mathrm{~mm}$ (see Fig. 3, bottom sinker). The base ring was made on a lathe, and the upper rings were made on a rolling machine. The surfaces of the upper rings were sandblasted with $250 \mu \mathrm{m}$ particles

${ }^{\mathrm{c}}$ Type 1.4301 stainless steel (equivalent to SAE/ANSI type 304) to be distinguished from the density sinker. This improved measurement system is capable of sorption measurements for both porous materials and non-porous materials (e.g., the sorption sinker) with simultaneous density measurement. Detailed information about the improved measurement system and the modifications are described in our previous work (Kleinrahm et al. 2019). Here, we only summarize the key information.

The temperature of the measuring cell was measured with a well-calibrated $100 \Omega$ platinum resistance thermometer (Lake Shore, USA, type: PT-103) in conjunction with a resistance bridge (Anton Paar, Austria, type: MKT50) and the calibrated internal resistor (approximately $400 \Omega$ ) of the bridge. The thermometer was calibrated in-house on ITS-90 at the triple point of water $(273.160 \mathrm{~K})$, the melting point of gallium (302.9146 K), and the freezing point of indium (429.7485 K). The pressure was measured with a vibrating quartz-crystal-type transmitter (range up to $13.8 \mathrm{MPa}$, Paroscientific, USA, type: $42 \mathrm{~K}-101$ ); the transmitter was thermostated at approximately $T=333.15 \mathrm{~K}$ to avoid condensation of the sample gas. The pressure measurement chain was annually calibrated in-situ with a piston gauge (Fluke Calibration, USA, type: PG-7601). The weighing of the sinker and the adsorbent was conducted with an analytical balance (readability: $1 \mu \mathrm{g}$, Mettler-Toledo, Switzerland, type: WXS206SDU) via the magnetic-suspension coupling. The density sinker was a $20 \mathrm{~g}$ titanium sinker with a relatively small surface-to-volume ratio and with the surface polished with abrasive. The sorption sinker was made of stainless steel (type 1.4301, according to the European standard) with a mass of about $9.3 \mathrm{~g}$ and a relatively large surfaceto-volume ratio; the surface of the sorption sinker was sandblasted with $250 \mu \mathrm{m}$ particles. Detailed information of these two sinkers are summarized in Table 1 . The expanded 
uncertainty $(k=2)$ of the measurement system was estimated to be: $16 \mathrm{mK}$ for temperature, between $(0.1$ and 0.7$) \mathrm{kPa}$ for pressures from vacuum to $8 \mathrm{MPa}$, and $0.020 \mathrm{~kg} \cdot \mathrm{m}^{-3}$ in density. The systematic error due to the FTE has been included in the uncertainty of density measurement. The combined expanded uncertainty $(k=2)$ in density measurements of pure fluids, with the exception of measuring points in the vicinity of the dew point and the critical point, is $3.8 \times 10^{-4} \rho$ or $0.024 \mathrm{~kg} \cdot \mathrm{m}^{-3}$, whichever is larger.

\section{Working equations}

\subsection{Determination of the fluid density and explanation of the force-transmission error}

The magnetic-suspension coupling transmits the loads of the density sinker and the adsorbent (container with porous material or sorption sinker) in the pressurized measuring cell to the balance, which is placed under ambient conditions. However, since neither the coupling housing nor the sample gas are completely magnetically neutral, a small systematic FTE occurs. To obtain the highest achievable accuracy, the FTE caused by the magnetic-suspension coupling of the improved measurement system was systematically investigated in our previous work (Kleinrahm et al. 2019). Here, we only summarize the key information.

According to the Archimedes (buoyancy) principle, the readings of the analytical balance at the positions MP1 $\left(W_{1}\right)$ and MP2 $\left(W_{2}\right)$ reflect the mass $m_{\mathrm{S}}$ and volume $V_{\mathrm{S}}$ of the density sinker and the density of the fluid $\rho_{\text {fluid }}$ in the measuring cell. The weighing results yield:

$\left(W_{2}-W_{1}\right)_{\text {fluid }}=\left(m_{\mathrm{S}}-\rho_{\text {fluid }} \cdot V_{\mathrm{S}}\right) \cdot \alpha \cdot \phi_{12}$,

where $\alpha=\left(1-\rho_{\text {air }} / \rho_{\text {calib }}\right)^{-1}$ is the balance calibration factor with $\rho_{\text {air }}$ being the air density in the laboratory and $\rho_{\text {calib }}$ being the density of the calibration mass in the balance. The value $\phi_{12}$ is the coupling factor, which accounts for the FTE (due to the change in height of the permanent magnet) between positions MP1 and MP2. The coupling factor $\phi_{12}$ can be divided into two parts, an apparatus contribution, $\varepsilon_{\mathrm{vac}, 12}$, and a fluid contribution, $\varepsilon_{\text {fluid, } 12}$; the relation is:

$\phi_{12}=1+\varepsilon_{\text {vac }, 12}+\varepsilon_{\text {fluid, } 12}$

The value $\varepsilon_{\text {vac, } 12}$ should be calculated from the result of a measurement with the measuring cell evacuated, before or after an isothermal measurement of a fluid:

$\varepsilon_{\mathrm{vac}, 12}=\frac{m_{\mathrm{S}, \mathrm{vac}}^{*}}{m_{\mathrm{S}}}-1$, where $m_{\mathrm{S} \text {,vac }}^{*}=\left(W_{2}-W_{1}\right)_{\mathrm{vac}} / \alpha$. The value of $\varepsilon_{\text {fluid,12 }}$ is approximately proportional to the specific magnetic susceptibility $\chi_{\mathrm{s}}$ and the density $\rho_{\text {fluid }}$ of the sample fluid as demonstrated by McLinden et al. (2007):

$\varepsilon_{\text {fluid }, 12}=\varepsilon_{\rho, 12} \cdot \frac{\chi_{\mathrm{s}}}{\chi_{\mathrm{s} 0}} \cdot \frac{\rho_{\text {fluid }}}{\rho_{0}}$,

where $\varepsilon_{\rho, 12}$ is the constant of proportionality, $\chi_{\mathrm{s} 0}=10^{-8} \mathrm{~m}^{3} \cdot \mathrm{kg}^{-1}$ and $\rho_{0}=1000 \mathrm{~kg} \cdot \mathrm{m}^{-3}$ are reducing constants. The value of $\varepsilon_{\rho, 12}$ can be determined by measurements of synthetic air, as described by Kleinrahm et al. (2019). The present experimental values are $\varepsilon_{\mathrm{vac}, 12}=(-57 \pm 8) \times 10^{-6}$ and $\varepsilon_{\rho, 12}=(66 \pm 6) \times 10^{-6}$ for the density sinker used in the top position of our improved measurement system. Please note that these two values depend on the mass of the sinker, and they will be different for other instruments. Values for the specific magnetic susceptibility for several fluids are given in our previous paper, e.g., $\chi_{\mathrm{s}} / \chi_{\mathrm{s} 0}=-0.61$ for carbon dioxide. Rearranging Eqs. (1), (2), (3) and (4) yields the equation to calculate the fluid density:

$\rho_{\text {fluid }}=\frac{m_{\mathrm{S}, \text { vac }}^{*}-m_{\mathrm{S}, \text { fluid }}^{*}}{V_{\mathrm{S}}} \cdot\left(1+\varepsilon_{\mathrm{vac}, 12}+\varepsilon_{\rho, 12} \cdot \frac{\chi_{\mathrm{S}}}{\chi_{\mathrm{S} 0}} \cdot \frac{\rho_{\text {fluid }}-\rho_{\mathrm{S}}}{\rho_{0}}\right)^{-1}$,

where $m_{\text {S,fluid }}^{*}=\left(W_{2}-W_{1}\right)_{\text {fluid }} / \alpha$, and $\rho_{\mathrm{S}}=m_{\mathrm{S}} / V_{\mathrm{S}}$ is the density of the sinker. A detailed derivation of Eq. (5) is given in our previous paper (Kleinrahm et al. 2019); the last term in the parentheses in Eq. (5) was defined there as the "fluidspecific effect" $\varepsilon_{\mathrm{fse}}$. Please note that the volume of the sinker $V_{\mathrm{S}}$ depends on temperature and pressure. If the FTE were not taken into account, $m^{*}$ S,vac would be replaced by the actual calibrated mass of the sinker $m_{\mathrm{S}}$, and this would cause a typical error of $0.23 \mathrm{~kg} \cdot \mathrm{m}^{-3}$ (Kleinrahm et al. 2019). Furthermore, if the terms in the parentheses in Eq. (5) were omitted, this would cause a typical error of $550 \times 10^{-6} \cdot \rho_{\text {fluid }}$ (Kleinrahm et al. 2019).

\subsection{Uncertainty of the fluid density}

The uncertainty in density calculated with Eq. (5) was presented in our previous work (Kleinrahm et al. 2019). For a gravimetric sorption analyzer, density and adsorption are measured simultaneously while the latter one is the target. In this context, density can be either measured with the sorption analyzer and calculated with Eq. (5), or alternatively it could be calculated with a reference EOS using the measured temperature and pressure (and the analyzed composition in case of gas mixtures). In many cases, the densities of pure gases calculated with an EOS will yield a lower uncertainty. However, when gas mixtures are under investigation, Eq. (5) is recommended because even the state-of-the-art reference EOS for most gas mixtures 
cannot ensure a relative uncertainty better than $0.1 \%$. For pure fluids for which reliable reference EOS exist (e.g., the equation of Span and Wagner from 1996 for $\mathrm{CO}_{2}$ has a relative uncertainty in density ranging from $0.03 \%$ to $0.05 \%$ at pressures up to $30 \mathrm{MPa}$ and temperatures up to $523 \mathrm{~K}$ ) and when the measured temperature and pressure are accurate enough (e.g., with an uncertainty in the order of $50 \mathrm{mK}$ and $1.0 \mathrm{kPa}$, respectively, or less), the gas densities can be calculated with the reference EOS. In the present work, pure carbon dioxide was investigated, and the uncertainties in temperature and pressure measurements were low (see Sect. 2.2), and therefore, the densities were calculated with the reference EOS (Span and Wagner 1996). The combined expanded uncertainty in density $u_{\mathrm{C}}(\rho)$ including the uncertainties in temperature and pressure was then calculated by

$u_{\mathrm{C}}(\rho)=\left[u_{\mathrm{EOS}}(\rho)^{2}+\left(\left(\frac{\partial \rho}{\partial T}\right)_{p} \cdot u(T)\right)^{2}+\left(\left(\frac{\partial \rho}{\partial p}\right)_{T} \cdot u(p)\right)^{2}\right]^{0.5}$,

where $u_{\mathrm{EOS}}(\rho)$ is the uncertainty in density of the reference EOS, and the partial derivatives were calculated with the reference EOS as well.

\subsection{Determination of the adsorption on porous and non-porous material}

In order to determine the absolute amount of adsorbed mass $m_{\text {sorp }}$ on the adsorbent, Eq. (1) has to be extended to:

$\left(W_{1}-W_{0}\right)_{\text {fluid }}=\left[m_{\mathrm{CP}}-\rho_{\text {fluid }} \cdot\left(V_{\mathrm{CP}}+V_{\text {sorp }}\right)+m_{\text {sorp }}\right] \cdot \alpha \cdot \phi_{01}$,

where $W_{0}$ and $W_{1}$ are the balance readings at the positions ZP and MP1, respectively, and $m_{\text {sorp }}$ and $V_{\text {sorp }}$ are the mass and volume of the adsorbed fluid. For a porous material, $m_{\mathrm{CP}}=\left(m_{\mathrm{C}}+m_{\mathrm{P}}\right)$ and $V_{\mathrm{CP}}=\left(V_{\mathrm{C}}+V_{\mathrm{P}}\right)$, where $m_{\mathrm{C}}$ and $V_{\mathrm{C}}$ are the mass and the volume of the container together with its lifting rod, and $m_{\mathrm{P}}$ and $V_{\mathrm{P}}$ are the mass and the volume of the porous sample inside the container. For a non-porous material, e.g., a sorption sinker instead of the container (see Fig. 3), $m_{\mathrm{CP}}$ and $V_{\mathrm{CP}}$ are the mass $m_{\mathrm{S}}$ and the volume $V_{\mathrm{S}}$ of the sorption sinker. The value $\phi_{01}$ is the coupling factor, which accounts for the FTE between the positions $\mathrm{ZP}$ and MP1; it was determined in the same way as the value $\phi_{12}$ using analogously Eqs. (2) to (4), but with the mass $m_{\mathrm{CP}}$ of the adsorbent instead of the mass of the sinker $m_{\mathrm{S}}$. For our improved measurement system, the values of $\varepsilon_{\text {vac }, 01}$ and $\varepsilon_{\text {fluid, } 01}$ are $(-34 \pm 8) \times 10^{-6}$ and $(3 \pm 1) \times 10^{-6}$, respectively. With $V_{\text {sorp }}=m_{\text {sorp }} / \rho_{\text {sorp }}$, where $\rho_{\text {sorp }}$ corresponds to the density of the adsorbed fluid, Eq. (7) can be rearranged to: $m_{\text {sorp }}=\left[\frac{m_{\mathrm{CP}, \text { fluid }}^{*}}{\phi_{01}}-m_{\mathrm{CP}}+\rho_{\text {fluid }} V_{\mathrm{CP}}\right] \cdot\left(\frac{\rho_{\text {sorp }}-\rho_{\text {fluid }}}{\rho_{\text {sorp }}}\right)^{-1}$,

with $m_{\mathrm{CP}, \text { fluid }}{ }=\left(W_{1}-W_{0}\right)_{\text {fluid }} / \alpha$. Since the mass of the porous sample $m_{\mathrm{P}}$ was difficult to determine using a similar mass calibration technique as that for the solid sinkers, a measurement was carried out in an evacuated measurement cell after the activation of the porous sample. The value of $m_{\mathrm{P}}$ was then calculated by

$m_{\mathrm{P}}=m_{\mathrm{CP}}-m_{\mathrm{C}}=\frac{m_{\mathrm{CP}, \mathrm{vac}}^{*}}{\left(\varepsilon_{\mathrm{vac}, 01}+1\right)}-m_{\mathrm{C}}$,

where $m^{*}{ }_{\mathrm{CP}, \mathrm{vac}}=\left(W_{1}-W_{0}\right)_{\mathrm{vac}} / \alpha$. The coupling factor $\varepsilon_{\mathrm{vac}, 01}$ was calculated analogously to Eq. (3), where the porous sample inside the container was replaced by a non-porous sample of a similar mass $m_{\mathrm{P}}$. Combining Eqs. (8) and (9) yields the result:

$$
\begin{aligned}
m_{\text {sorp }}= & {\left[\frac{m_{\mathrm{CP}, \text { fluid }}^{*}}{1+\varepsilon_{\text {vac }, 01}+\varepsilon_{\text {fluid }, 01}}-\frac{m_{\mathrm{CP}, \text { vac }}^{*}}{1+\varepsilon_{\text {vac }, 01}}+\rho_{\text {fluid }} V_{\mathrm{CP}}\right] } \\
& \cdot\left(\frac{\rho_{\text {sorp }}-\rho_{\text {fluid }}}{\rho_{\text {sorp }}}\right)^{-1}
\end{aligned}
$$

Equation (10) can also be used for the determination of the adsorbed mass on non-porous material (e.g., a sorption sinker). The influence of the FTE on the adsorbed mass $m_{\text {sorp }}$ is taken into account by the terms $\varepsilon_{\text {vac, } 01}$ and $\varepsilon_{\text {fluid, } 01}$. If the FTE were not taken into account, $m_{\mathrm{CP} \text {,vac }}^{*}$ would be replaced by the actual calibrated mass of the adsorbent $m_{\mathrm{CP}}$ (this would cause an error of $m_{\mathrm{CP}} \cdot \varepsilon_{\mathrm{vac}, 01}$ ), and the terms $\varepsilon_{\text {vac }, 01}$ and $\varepsilon_{\text {fluid, } 01}$ would be equal to zero in Eq. (10). It is important to note that, although the excess amount of adsorbed mass ( $m^{\text {ex }}=m_{\text {sorp }}-\rho_{\text {fluid }} \cdot V_{\text {sorp }}$ by definition) does not require the term $\left[\left(\rho_{\text {sorp }}-\rho_{\text {fluid }}\right) / \rho_{\text {sorp }}\right]^{-1}$ and is an accepted thermodynamic quantity to report gas adsorption (Nguyen et al. 2018), the absolute one, as calculated by Eqs. (8) and (10), is presented in this work. The main reasons are: (1) most of the commonly used physically-based models for adsorption isotherms [e.g., Langmuir, Toth (1971) and Sips (1948) models] calculate the absolute adsorption; (2) it would be more useful to present the most comprehensive uncertainly analysis here, which can only be done by the analysis of the absolute adsorption and which can be easily simplified for the analysis of the excess adsorption.

The adsorption capacity of a porous material $q_{\mathrm{P}}$ and of a non-porous material $q_{\mathrm{NP}}$ can now be expressed by

$q_{\mathrm{P}}=\left(m_{\text {sorp }} / M_{\text {fluid }}\right) / m_{\mathrm{P}}$,

and 
$q_{\mathrm{NP}}=\left(m_{\text {sorp }} / M_{\text {fluid }}\right) / A_{\mathrm{NP}}$,

respectively, where $M_{\text {fluid }}$ is the molar mass of the investigated fluid and $A_{\mathrm{NP}}$ is the estimated geometrical surface area of the sorption sinker (i.e., the area calculated by the overall geometry of the sinker and not including the effects of surface roughness). For porous materials, the adsorbed mass on the container surfaces can usually be neglected because its share is very small in comparison to the adsorbed mass on the porous sample.

\subsection{Uncertainty of the adsorption}

The combined uncertainty of the adsorbed mass can be determined according to the "Guide to the Expression of Uncertainty in Measurement" (ISO/IEC Guide 98-3 2008; GUM:1995) by applying the error propagation to Eq. (10) and simplifying it to:

$$
\begin{aligned}
& u_{\mathrm{C}}\left(m_{\text {sorp }}\right)^{2}=\left\{u\left(m_{\text {CP, fluid }}^{*}\right)^{2}+u\left(m_{\mathrm{CP}, \text { vac }}^{*}\right)^{2}+\left[V_{\mathrm{CP}} \cdot u_{\mathrm{C}}\left(\rho_{\text {fluid }}\right)\right]^{2}+\left[\rho_{\text {fluid }} \cdot u\left(V_{\mathrm{CP}}\right)\right]^{2}\right\} \\
& \cdot\left(1-\frac{\rho_{\text {fluid }}}{\rho_{\text {sorp }}}\right)^{-2}+\frac{\left(m_{\text {sorp }}\right)^{2}}{\left(\rho_{\text {sorp }}-\rho_{\text {fluid }}\right)} \cdot\left[u\left(\rho_{\text {fluid }}\right)+\frac{\rho_{\text {fluid }}}{\rho_{\text {sorp }}} \cdot u\left(\rho_{\text {sorp }}\right)\right]^{2}
\end{aligned}
$$

The major simplifications were the omission of the terms and the uncertainties of the apparatus contribution of the FTE $\varepsilon_{\text {vac }}$ and the fluid contribution of the FTE $\varepsilon_{\text {fluid }}$. The value of $\varepsilon_{\text {vac }}$ has an absolute uncertainty of approximately $8 \times 10^{-6}$ (Kleinrahm et al. 2019) and the sensitivity coefficient (which is approximately $\rho_{\text {fluid }} \cdot V_{\mathrm{CP}}$ ) for $u\left(\varepsilon_{\text {vac }}\right)$ is in the order of $0.1 \mathrm{~g}$ (assuming a gas density $\rho_{\text {fluid }}$ of $100 \mathrm{~kg} \cdot \mathrm{m}^{-3}$ and a sample volume $V_{\mathrm{CP}}$ of $\left.1.0 \mathrm{~cm}^{3}\right)$; therefore, the uncertainty contribution of $\varepsilon_{\mathrm{vac}}$ to $u_{\mathrm{C}}\left(m_{\mathrm{sorp}}\right)$ is less than $1 \mu \mathrm{g}$. The value of $\varepsilon_{\text {fluid }}$ is in the order of $3 \times 10^{-6}$ and its relative uncertainty is $10 \%$ (Kleinrahm et al. 2019). The sensitivity coefficient for $u\left(\varepsilon_{\text {fluid }}\right)$ is less than $10 \mathrm{~g}$ (assuming the mass of the adsorbent $m_{\mathrm{CP}}<10 \mathrm{~g}$ ); therefore, the uncertainty contribution of $\varepsilon_{\text {fluid }}$ to $u_{\mathrm{C}}\left(m_{\text {sorp }}\right)$ is less than $3 \mu \mathrm{g}$. Please note that, although the influence of the terms and the uncertainties of $\varepsilon_{\text {vac }}$ and $\varepsilon_{\text {fluid }}$ to the combined uncertainty of the adsorbed mass $u_{\mathrm{C}}\left(m_{\text {sorp }}\right)$ is negligibly small, it does not mean that the influence of the FTE to the value of the adsorbed mass $m_{\text {sorp }}$ can be neglected in all cases (see further discussions in Sects. 4.2 and 5.2).

By applying the error propagation to Eq. (11), the relative combined uncertainty of the adsorption capacity of a porous material $u_{\mathrm{C}}\left(q_{\mathrm{P}}\right) / q_{\mathrm{P}}$ can be calculated by

$\left[\frac{u_{\mathrm{C}}\left(q_{\mathrm{P}}\right)}{q_{\mathrm{P}}}\right]^{2}=\left[\frac{u_{\mathrm{C}}\left(m_{\text {sorp }}\right)}{m_{\text {sorp }}}\right]^{2}+\left[\frac{u\left(m_{\mathrm{P}}\right)}{m_{\mathrm{P}}}\right]^{2}$,

where the uncertainty of the molar mass was negligibly small, and the term $u\left(\rho_{\text {fluid }}\right) / \rho_{\text {sorp }}$ in Eq. (13) can be neglected because it is in the order of a few $10^{-5}$. At low fluid densities, Eq. (14) underestimates the uncertainty in $q_{\mathrm{p}}$ because uncertainties in the weighings place a lower limit on the absolute combined uncertainty of $q_{\mathrm{P}}$ :

$u_{\mathrm{C}, \min }\left(q_{\mathrm{P}}\right)^{2}=\frac{u\left(m_{\mathrm{CP}, \text { fluid }}^{*}\right)^{2}+u\left(m_{\mathrm{CP}, \text { vac }}^{*}\right)^{2}}{\left(M_{\text {fluid }} \cdot m_{\mathrm{P}}\right)^{2}}$,

When a non-porous material is investigated, the relative combined uncertainty of the adsorption capacity of a nonporous material $u_{\mathrm{C}}\left(q_{\mathrm{NP}}\right) / q_{\mathrm{NP}}$ can be calculated by applying the error propagation to Eq. (12) and simplifying to:

$\left[u_{\mathrm{C}}\left(q_{\mathrm{NP}}\right)\right]^{2}=\left[\frac{u_{\mathrm{C}}\left(m_{\text {sorp }}\right)}{m_{\text {sorp }}}\right]^{2} \cdot q_{\mathrm{NP}}^{2}$,

where the uncertainty of the molar mass was negligibly small. The term $u\left(A_{\mathrm{NP}}\right) / A_{\mathrm{NP}}$, estimated to be $1.0 \%$, was neglected as well, because it was relatively small compared to the term $u_{\mathrm{C}}\left(m_{\text {sorp }}\right) / m_{\text {sorp }}$, which was generally larger than $10.0 \%$. The value $u_{\mathrm{C}}\left(m_{\text {sorp }}\right)$ in Eq. (16) was calculated according to Eq. (13). However, since the adsorbed mass $m_{\text {sorp }}$ was less than $50 \mu \mathrm{g}$ in the pressure range $p<0.99 \cdot p_{\mathrm{s}}$, where $p_{\mathrm{s}}$ is the dew-point pressure, and in the order of $200 \mu \mathrm{g}$ in the pressure range $0.99 \cdot p_{\mathrm{s}} \leq p<p_{\mathrm{s}}$ (see Sect. 5.1), the contribution of the terms multiplied by $\left(m_{\text {sorp }}\right)^{2}$ in Eq. (13) to $u_{\mathrm{C}}\left(m_{\text {sorp }}\right)$ is less than $5 \mu \mathrm{g}$, which is much smaller than the first term and can therefore be neglected. The minimum absolute combined uncertainty in $q_{\mathrm{NP}}$ can be estimated by

$u_{\mathrm{C}, \min }\left(q_{\mathrm{NP}}\right)^{2}=\frac{u\left(m_{\mathrm{CP}, \text { fluid }}^{*}\right)^{2}+u\left(m_{\mathrm{CP}, \mathrm{vac}}^{*}\right)^{2}}{\left(M_{\text {fluid }} \cdot A_{\mathrm{NP}}\right)^{2}}$,

for fluid densities $\rho_{\text {fluid }}$ less than about $10 \mathrm{~kg} \mathrm{~m}^{-3}$.

\section{Sorption measurement on porous materials}

\subsection{Measurements and results}

Test measurements of the adsorption of carbon dioxide on zeolite 13X were conducted with our improved measurement system used as a gravimetric sorption analyzer. Measurements were carried out along the isotherm $T=283.144 \mathrm{~K}$ with pressure-increasing steps from $p=0.0001 \mathrm{MPa}$ up to the dew-point pressure and then with pressure-decreasing steps. Information of the carbon dioxide sample is summarized in Table 2; it was used as received from the supplier without further gas analysis or purification. The zeolite 13X sample (Chemiewerk Bad Köstritz GmbH, Germany, type: 
Table 2 Sample information

\begin{tabular}{llll}
\hline Chemical name & Source & Purity/mole fraction & $\begin{array}{l}\text { Purification } \\
\text { method }\end{array}$ \\
\hline Carbon dioxide & Air Products & $0.999995^{\mathrm{a}}$ & None \\
Helium & Air Liquide & $0.99999^{\mathrm{b}}$ & None \\
\hline
\end{tabular}

${ }^{a}$ Impurities (stated by supplier): $x\left(\mathrm{H}_{2} \mathrm{O}\right) \leq 2.0 \times 10^{-6}, x\left(\mathrm{O}_{2}\right) \leq 0.5 \times$ $10^{-6}, x\left(\mathrm{C}_{\mathrm{m}} \mathrm{H}_{\mathrm{n}}\right) \leq 0.1 \times 10^{-6}, x\left(\mathrm{~N}_{2}\right) \leq 2.0 \times 10^{-6}, x(\mathrm{CO}) \leq 0.5 \times 10^{-6}$, where $x$ denotes mole fraction

${ }^{\mathrm{b}}$ Impurities (stated by supplier): $x\left(\mathrm{H}_{2} \mathrm{O}\right) \leq 2.0 \times 10^{-6}, x\left(\mathrm{O}_{2}\right) \leq 2.0 \times$ $10^{-6}, x\left(\mathrm{C}_{\mathrm{m}} \mathrm{H}_{\mathrm{n}}\right) \leq 0.2 \times 10^{-6},\left(\mathrm{~N}_{2}\right) \leq 0.5 \times 10^{-6}$

Köstrolith 13 XBFK, surface $A=500 \mathrm{~m}^{2} \cdot \mathrm{g}^{-1}$ ) was provided in binder-free ball granules (diameter of approximately $2 \mathrm{~mm}$ ) and was used as received. Before an isothermal measurement, the zeolite sample was activated inside the measuring cell at a temperature $T=523 \mathrm{~K}$ and a pressure less than $0.1 \mathrm{~Pa}$ for at least $4 \mathrm{~h}$ (overnight for the very first time of activation after the sample was put into the measuring cell). The mass of the zeolite sample $m_{\mathrm{P}}$ was obtained after activation by weighing it in the evacuated measurement cell using Eq. (9); the volume of the sample $V_{\mathrm{P}}$ was determined by measuring the buoyancy force on the sample in helium at $T=293.15 \mathrm{~K}$ and $p$ at $(2.0,4.0,6.0$ and 8.0) MPa, with the assumption that helium is not adsorbed on zeolite. Although it has been shown that this assumption may be problematic (Maggs et al. 1960; Malbrunot et al. 1997; Hocker et al. 2003; Pini 2014; and Brandani et al. 2016), this volume determination method is by far the most commonly used and the most reliable one available to us. Besides, we estimated the relative uncertainty of $V_{\mathrm{P}}$ to be as large as $2.0 \%$ (see Sect. 4.2), compared to which, the uncertainty of $V_{\mathrm{P}}$ attributed to this assumption (hard to quantify) should be negligibly small, otherwise obvious helium adsorption would be observed. Information for the helium sample is summarized in Table 2; the density of helium was calculated with a reference EOS (Ortiz-Vega 2013). The mass and volume of the zeolite sample were $m_{\mathrm{P}}=(2.1549 \pm 0.0431) \mathrm{g}$ and $V_{\mathrm{P}}=(0.3415 \pm 0.0068) \mathrm{cm}^{3}$; the second value within the parentheses is the expanded uncertainty $(k=2)$. The sample container for the zeolite sample was a hollow cylinder (outer diameter: $16 \mathrm{~mm}$, wall thickness: $0.5 \mathrm{~mm}$, height: $20 \mathrm{~mm}$, material: stainless steel) with a bottom plate and a hanger on top. The mass and the volume of the container were $m_{\mathrm{C}}=(2.4093 \pm 0.0004) \mathrm{g}$ and $V_{\mathrm{C}}=(0.30466 \pm 0.00035)$ $\mathrm{cm}^{3}$ using typical mass and volume calibration methods for solids.

The measurement results are listed in Table 3 and illustrated in Fig. 4. It can be seen that the adsorption shows a typical type I curve (Brunauer et al. 1940), which is the wellknown Langmuir adsorption isotherm, i.e., the adsorbed mass increases significantly at low pressure $\left(p / p_{\mathrm{s}}<0.05\right)$ and then reaches a plateau until close to the dew-point pressure. When the dew-point pressure was approached, the adsorption capacity increased again, implying the effect of the capillary condensation. The results are in good agreement with literature (e.g., Cavenati et al. 2004).

\subsection{Uncertainty analysis}

As has been discussed in Sect. 2.2, for our improved measurement system, the expanded uncertainty $(k=2)$ in temperature and pressure measurements are $16 \mathrm{mK}$ and $(0.2$ to 0.7$) \mathrm{kPa}$, respectively. The relative expanded uncertainty $(k=2)$ in density calculated with equation of Span and Wagner (1996) over the investigated $(p, T)$ range was $0.03 \%$. The combined uncertainty in the density of the sample fluid was calculated by Eq. (6). The expanded uncertainty $(k=2)$ of $m^{*}{ }_{\text {CP,vac }}$ and $m_{\text {CP,fluid }}^{*}$ was estimated to be $60 \mu \mathrm{g}$ according to the fluctuation of the weighing values. The major contribution to the uncertainty $(k=2)$ of the volume of the adsorbent $V_{\mathrm{CP}}$ was the uncertainty of the volume of the zeolite sample $V_{\mathrm{P}}$, which was estimated by

$u\left(V_{\mathrm{P}}\right)^{2}=\frac{u\left(m_{\mathrm{CP}, \text { fluid }}^{*}\right)^{2}+u\left(m_{\mathrm{CP} \text {,vac }}^{*}\right)^{2}}{\rho_{\mathrm{He}, 293.15 \mathrm{~K}}^{2}}$,

and thus $u\left(V_{\mathrm{CP}}\right)=u\left(V_{\mathrm{P}}\right)=0.0034 \mathrm{~cm}^{3}$. The standard uncertainty of the mass of the zeolite sample was estimated to be $u\left(m_{\mathrm{P}}\right)=0.02155 \mathrm{~g}$, corresponding to a sample purity of 99.0 mass-\%. (In other words, the impurities in the zeolite sample, which amount to $1 \%$ of $\left(m_{\mathrm{P}}=2.1549 \mathrm{~g}\right)$, are assumed not to adsorb gases).

The value of $\rho_{\text {sorp }}$ is commonly estimated as the saturated-liquid density at the standard boiling point pressure $0.1 \mathrm{MPa}$ (e.g., Dreisbach et al. 1999; Cavenati et al. 2004). However, since the triple-point pressure of carbon dioxide $p_{\text {tr }}=0.518 \mathrm{MPa}$ at $T_{\text {tr }}=216.6 \mathrm{~K}$ is greater than $0.1 \mathrm{MPa}$, the value of $\rho_{\text {sorp }}$ was estimated to be the saturated-liquid density at the pressure $p_{\text {tr }}$, i.e., $\rho_{\text {sorp }}=1178 \mathrm{~kg} \mathrm{~m}^{-3}$ as calculated with the reference EOS for carbon dioxide (Span and Wagner 1996). For a porous material as an adsorbent, we assume that the true density $\rho_{\text {sorp }}$ of the adsorbed sample fluid (which was carbon dioxide in the present case) on the surface of the porous zeolite can be considerably larger than the saturated-liquid density at the triple-point temperature of carbon dioxide, especially for the first molecular layer on the surface. We estimate that this assumption involves a relative expanded uncertainty $(k=2)$ of $10 \%$, which could, however, be significantly larger.

For a non-porous material as an adsorbent (e.g., our sorption sinker, see Fig. 3), we assume that the first molecular layer on its surface has the same density as on the porous zeolite. In the vicinity of the dew-point pressure, however, 
Table 3 Adsorption capacity $q_{\mathrm{P}}$ of zeolite $13 \mathrm{X}$ for carbon dioxide along the isotherm $T=283.144 \mathrm{~K}$ and the relative combined expanded uncertainty $(k=2) U_{\mathrm{C}}\left(q_{\mathrm{P}}\right) / q_{\mathrm{P}}$, where $T$ is the temperature (ITS-90) and $p$ is the pressure

\begin{tabular}{llllllll}
\hline$T / \mathrm{K}$ & $p / \mathrm{MPa}$ & $q_{\mathrm{P}} /\left(\mathrm{mmol} \mathrm{g}^{-1}\right)$ & $U_{\mathrm{C}}\left(q_{\mathrm{P}}\right) / q_{\mathrm{P}} \cdot 100$ & $T / \mathrm{K}$ & $p / \mathrm{MPa}$ & $q_{\mathrm{P}} /\left(\mathrm{mmol} \mathrm{g}^{-1}\right)$ & $U_{\mathrm{C}}\left(q_{\mathrm{P}}\right) / q_{\mathrm{P}} \cdot 100$ \\
\hline 283.164 & 0.0001 & 0.0163 & 5.83 & 283.165 & 3.9881 & 7.4934 & 2.20 \\
283.186 & 0.0042 & 2.8150 & 2.00 & 283.146 & 4.2039 & 7.5597 & 2.24 \\
283.176 & 0.0118 & 3.8814 & 2.00 & 283.140 & 4.4040 & 7.6584 & 2.28 \\
283.166 & 0.0176 & 4.2648 & 2.00 & 283.137 & 4.4444 & 7.7155 & 2.29 \\
283.161 & 0.0379 & 4.8956 & 2.00 & 283.137 & 4.4572 & 7.7497 & 2.30 \\
283.157 & 0.0458 & 5.0425 & 2.00 & 283.126 & 4.4667 & 7.7871 & 2.30 \\
283.161 & 0.0590 & 5.2144 & 2.00 & 283.117 & 4.4770 & 7.8449 & 2.30 \\
283.151 & 0.0684 & 5.3198 & 2.00 & 283.112 & 4.4864 & 7.9459 & 2.31 \\
283.138 & 0.0796 & 5.4189 & 2.00 & 283.131 & 4.4968 & 8.1605 & 2.31 \\
283.137 & 0.0887 & 5.4906 & 2.00 & 283.160 & $4.5088^{\mathrm{a}}$ & 8.5585 & 8.04 \\
283.130 & 0.0987 & 5.5595 & 2.00 & 283.156 & $4.5082^{\mathrm{a}}$ & 8.8643 & 8.01 \\
283.128 & 0.1191 & 5.6736 & 2.00 & 283.142 & $4.5044^{\mathrm{a}}$ & 9.0577 & 7.99 \\
283.136 & 0.1394 & 5.7660 & 2.00 & 283.129 & 4.4934 & 8.6850 & 2.31 \\
283.139 & 0.1591 & 5.8446 & 2.00 & 283.136 & 4.4840 & 8.0751 & 2.30 \\
283.147 & 0.1799 & 5.9139 & 2.00 & 283.136 & 4.4756 & 7.9181 & 2.30 \\
283.155 & 0.4914 & 6.4251 & 2.00 & 283.132 & 4.4630 & 7.8587 & 2.30 \\
283.166 & 0.9930 & 6.7524 & 2.01 & 283.121 & 4.4289 & 7.7750 & 2.29 \\
283.164 & 1.4912 & 6.9385 & 2.02 & 283.116 & 4.2479 & 7.6249 & 2.25 \\
283.173 & 1.9886 & 7.0729 & 2.03 & 283.114 & 4.0460 & 7.5639 & 2.21 \\
283.176 & 2.4895 & 7.1842 & 2.06 & 283.107 & 2.5099 & 7.2659 & 2.06 \\
283.171 & 2.9911 & 7.2843 & 2.09 & 283.096 & 2.0078 & 7.1640 & 2.03 \\
283.168 & 3.4929 & 7.3825 & 2.14 & & & & \\
\hline
\end{tabular}

The expanded uncertainties $(k=2)$ of the measurements are $16 \mathrm{mK}$ for temperature $T$, and between $(0.1$ and 0.7) $\mathrm{kPa}$ for pressure $p$. The needed densities $\rho_{\text {fluid }}$ (see Eqs. (10) and (11)) were calculated with the reference equation of state (Span and Wagner 1996) with a relative expanded uncertainty $(k=2)$ of $0.03 \%$

${ }^{\text {a }}$ State points in the gas-liquid coexistence region; the saturated pressure (e.g., $p_{\mathrm{s}}=4.5033 \mathrm{MPa}$ at $T_{\mathrm{s}}=283.160 \mathrm{~K}$ ) was estimated by the reference equation of state for carbon dioxide (Span and Wagner 1996)

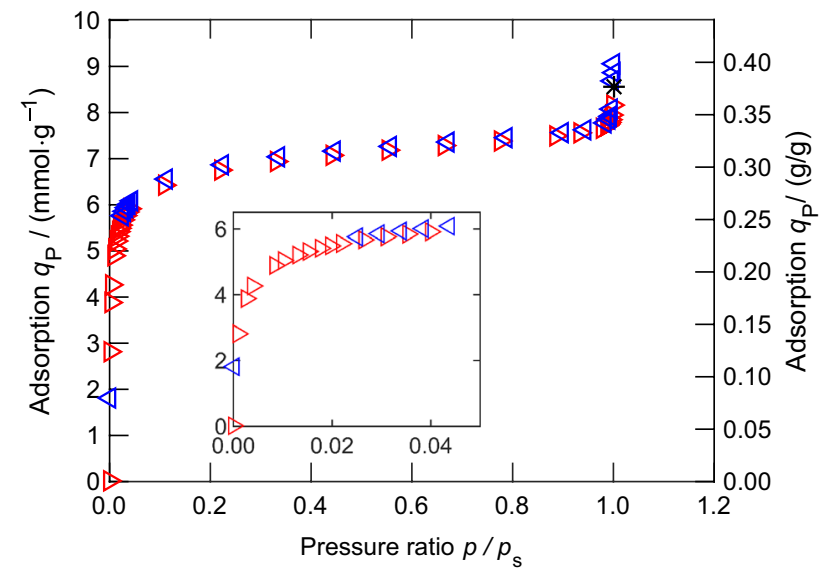

Fig. 4 Adsorption capacity $q_{\mathrm{P}}$ of zeolite $13 \mathrm{X}$ for carbon dioxide along the isotherm $T=283.144 \mathrm{~K}$. The expanded combined uncertainties are within the vertical size of the plotted symbols. The measurements were conducted with increasing $(\triangleright)$ and decreasing pressures $(\triangleleft)$. The turning point $(*)$ was in the gas-liquid coexistence region; the measured pressure $p=4.5088 \mathrm{MPa}$ was higher than the dew-point pressure $p_{\mathrm{s}}=4.5033 \mathrm{MPa}$, calculated with the reference equation of Span and Wagner (1996), at the measured temperature $T=283.160 \mathrm{~K}$ capillary condensation can occur, and a thin liquid film covers the surface; its (hypothetical) thickness can be in the order of up to about $0.1 \mu \mathrm{m}$ (see Fig. $5 \mathrm{c}$ ). We estimate the density $\rho_{\text {sorp }}$ of this liquid film (including the first adsorbed molecular layer) as the saturated-liquid density of carbon dioxide at the measured temperature $T=283.150 \mathrm{~K}$ to be $\rho_{\text {sorp }}=\rho_{\text {sat, }, \text { liq }}=861 \mathrm{~kg} \mathrm{~m}^{-3}$ [calculated with the reference EOS of Span and Wagner (1996)]. Furthermore, we estimate that this assumption $\rho_{\text {sorp }}=\rho_{\text {sat,liq }}$ involves a relative expanded uncertainty $(k=2)$ of $10 \%$, however, it could be much greater.

Since the surface area of zeolite $A_{\mathrm{NP}}$ is in the order of $500 \mathrm{~m}^{2} \cdot \mathrm{g}^{-1}$, while the surface area of the sample container was approximately $24.0 \mathrm{~cm}^{2}$, the adsorption on the walls of the sample container was ignored. The influence of this simplification on the resulting adsorption capacity is negligibly small (less than $3 \times 10^{-6}$ ). If the FTE was not taken into consideration, see Eq. (10) and the following comments, with $m_{\text {sorp }}(=700 \mathrm{mg})$ the error would be on the order of $0.2 \mathrm{mg}$ for the current case, which corresponds to approximately $0.002 \mathrm{mmol} \cdot \mathrm{g}^{-1}$ or $0.03 \%$ in adsorption capacity $q_{\mathrm{P}}$ for a typical $(p, T)$ state, and this was negligibly small. Hence, in 
Fig. 5 a, b Relative deviations of the experimental densities $\rho_{\exp }$ for carbon dioxide at $T=283.175 \mathrm{~K}$ from densities $\rho_{\text {EOS }}$ calculated with reference equation of state (Span and Wagner 1996). c, d Adsorption $q_{\mathrm{NP}}$ of carbon dioxide on the surface of the two solid sinkers. The saturated pressure of carbon dioxide at $T=283.175 \mathrm{~K}$ is $p_{\mathrm{s}}=4.5050 \mathrm{MPa}$. $\bigcirc$, measured with the density sinker; $\times$, measured with the sorption sinker (see Table 1). The dashed lines in panels (a) and (b) are the uncertainty boundaries $(k=2)$ of the reference equation. An error bar (expanded combined uncertainty $k=2$ ) for one measurement is plotted in each figure
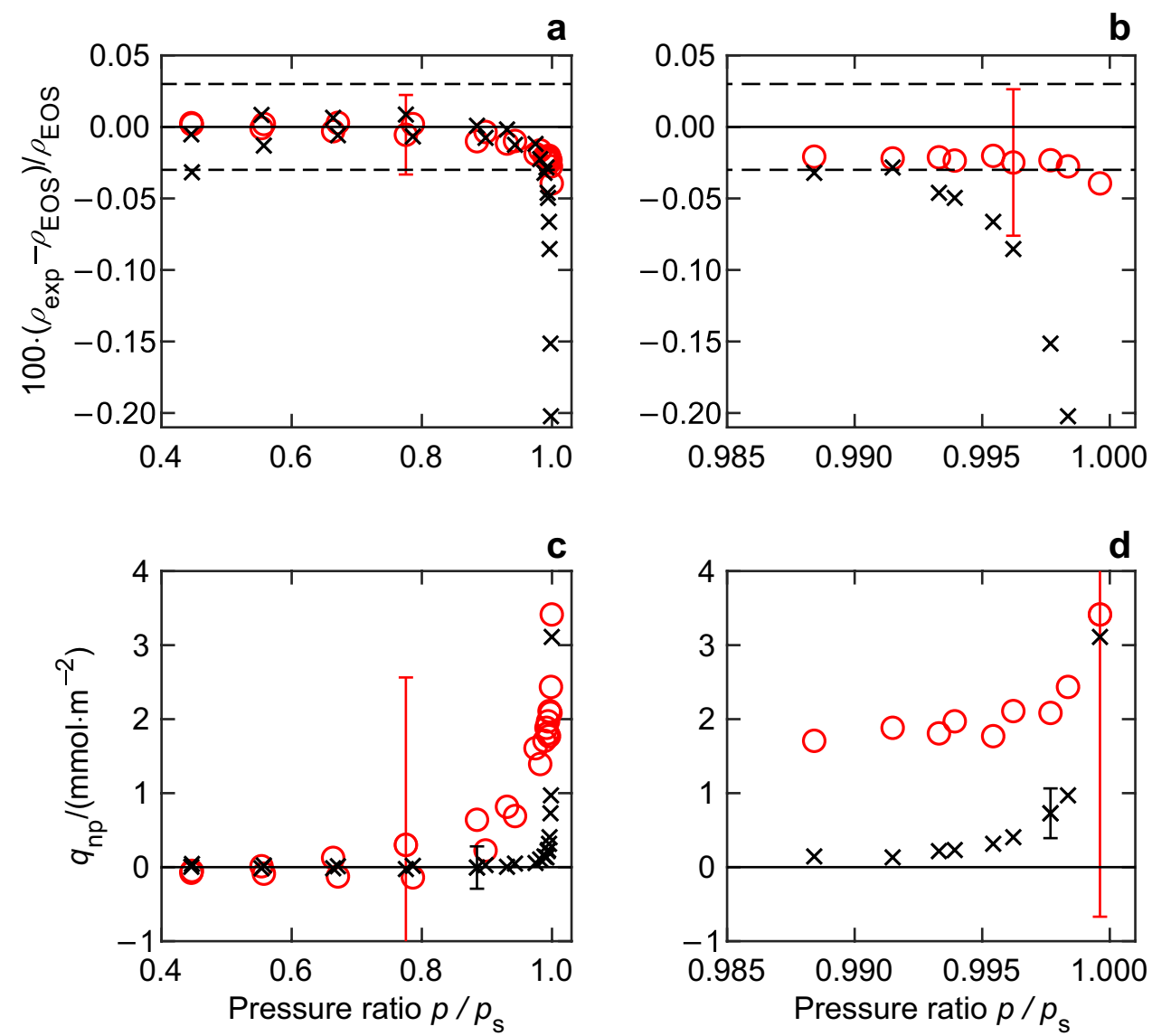

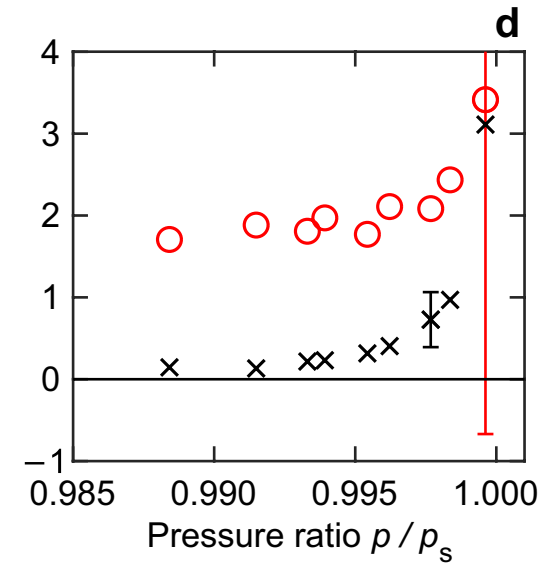

case of sorption measurements of gases (except for hydrogen and helium) on porous materials, the influence of the FTE on the determination of the adsorbed mass $m_{\text {sorp }}$ is negligibly small. Recent helium adsorption measurements on clinoptilolite carried out by Arami-Niya et al. (2019) using a gravimetric sorption analyzer obtained an adsorption capacity around $0.15 \mathrm{mmol} \cdot \mathrm{g}^{-1}$ or less at pressures below $5 \mathrm{MPa}$. In this case, the influence of the FTE may be non-negligible.

The relative combined expanded uncertainty $(k=2)$ of the adsorption capacity for each measuring point is listed in Table 3 . The uncertainty budget for the adsorption capacity $q_{\mathrm{P}}$ of zeolite $13 \mathrm{X}$ for carbon dioxide, measured with our improved measurement system, is summarized in Table 4; the measurement at $T=283.165 \mathrm{~K}$ and $p=3.9881 \mathrm{MPa}$ was taken as an example. As can be seen in Table 4, the uncertainty of the mass of the zeolite sample $u\left(m_{\mathrm{P}}\right)$ is the dominating one, followed by that of the density of the adsorbed fluid $u\left(\rho_{\text {sorp }}\right)$. The contribution of the volume of the adsorbent $u\left(V_{\mathrm{CP}}\right)$ to the uncertainty is one order lower than the previous two parameters, and those of the remaining parameters (temperature, pressure, fluid density in the gas phase, and weighing values) are negligibly small. Please note that, if the excess adsorption was presented rather than the absolute one, the second dominating uncertainty $u\left(\rho_{\text {sorp }}\right)$ can be ignored in the uncertainty calculation, i.e., the uncertainty of the measured excess adsorption is lower than that of the absolute one for porous materials. In summary, the uncertainty of the adsorption capacity of a porous material is largely attributed to the porous sample itself rather than to the measurement technique of the gravimetric sorption analyzer; this agrees with various studies (Hocker et al. 2003; Pini 2014; and Brandani et al. 2016), which concluded that the estimation of the mass and/or volume of the adsorbent involves a non-negligible uncertainty contribution to adsorption meausurements.

In Table 4, the uncertainty budget of a typical commercial gravimetric sorption analyzer is also listed. The expanded uncertainties $(k=2)$ in the measurements of temperature,

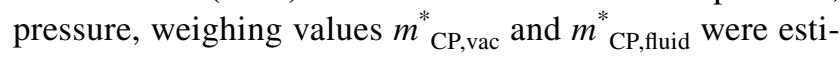
mated to be $300 \mathrm{mK}, 3.5 \mathrm{kPa}, 80 \mu \mathrm{g}$, and $80 \mu \mathrm{g}$, respectively. The uncertainty of the volume of the adsorbent would then change to $0.0090 \mathrm{~cm}^{3}$ according to Eq. (18). As seen in Table 4, the combined uncertainty in the adsorption capacity of zeolite $13 \mathrm{X}$ for carbon dioxide measured with a typical commercial gravimetric sorption analyzer is similar to that measured with our the improved measurement system; i.e., the improvement of our measurement system did not significantly reduce the uncertainty in the sorption measurement of carbon dioxide on zeolite 13X. However, if an adsorption system (gas on adsorbent) with much lower adsorption (e.g., 
Table 4 Uncertainty budget for the adsorption capacity $q_{\mathrm{P}}$ for carbon dioxide on zeolite $13 \mathrm{X}$ (see Eq. (14))

\begin{tabular}{|c|c|c|}
\hline Source $^{\mathrm{a}}$ & Uncertainty $U(k=2)$ & $\begin{array}{l}\text { Contribution } \\
\text { to } U_{\mathrm{C}}\left(q_{\mathrm{P}}\right) / q_{\mathrm{P}}\end{array}$ \\
\hline \multicolumn{3}{|l|}{ Our improved gravimetric sorption analyzer } \\
\hline Temperature $T$ & $16 \mathrm{mK}$ & $(0.0021 \%)$ \\
\hline Pressure $p$ & $0.2 \mathrm{kPa}$ & $(0.0018 \%)$ \\
\hline Density calculated with equation of Span and Wagner (1996) & $0.03 \%$ & $(0.0032 \%)$ \\
\hline Combined uncertainty in density of the sample fluid $U_{\mathrm{C}}(\rho)^{\mathrm{b}}$ & $0.043 \mathrm{~kg} \cdot \mathrm{m}^{-3}$ & $0.0043 \%$ \\
\hline Weighing value $m_{\mathrm{CP}, \text { vac }}^{*}(4.5897 \mathrm{~g})$ & $60 \mu \mathrm{g}$ & $0.0093 \%$ \\
\hline Weighing value $m_{\mathrm{CP} \text {,fluid }}^{*}(5.0703 \mathrm{~g})$ & $60 \mu \mathrm{g}$ & $0.0093 \%$ \\
\hline Volume of the adsorbent $U\left(V_{\mathrm{CP}}\right)\left(V_{\mathrm{CP}} \approx 0.6462 \mathrm{~cm}^{3}\right)$ & $0.0068 \mathrm{~cm}^{3}$ & $0.1136 \%$ \\
\hline Density of condensed fluid $U\left(\rho_{\text {sorp }}\right) / \rho_{\text {sorp }}{ }^{\mathrm{c}}$ & $10 \%$ & $0.9155 \%$ \\
\hline Mass of zeolite sample $m_{\mathrm{P}}(2.1549 \mathrm{~g})$ & $0.0431 \mathrm{~g}$ & $2.0000 \%$ \\
\hline Relative combined expanded uncertainty $(k=2)$ in adsorption capacity ${ }^{\mathrm{d}} U_{\mathrm{C}}\left(q_{\mathrm{P}}\right) / q_{\mathrm{P}}$ & & $2.2025 \%$ \\
\hline \multicolumn{3}{|l|}{ A typical commercial gravimetric sorption analyzer } \\
\hline Temperature $T$ & $300 \mathrm{mK}$ & $(0.0401 \%)$ \\
\hline Pressure $p$ & $3.5 \mathrm{kPa}$ & $(0.0158 \%)$ \\
\hline Density calculated with equation of Span and Wagner (1996) & $0.03 \%$ & $(0.0032 \%)$ \\
\hline Combined uncertainty in density of the sample fluid $U_{\mathrm{C}}(\rho)^{\mathrm{b}}$ & $0.055 \mathrm{~kg} \cdot \mathrm{m}^{-3}$ & $0.0433 \%$ \\
\hline Weighing value $m_{\mathrm{CP}, \text { vac }}^{*}(4.5897 \mathrm{~g})$ & $80 \mu \mathrm{g}$ & $0.0124 \%$ \\
\hline Weighing value $m_{\mathrm{CP} \text {,fluid }}^{*}(5.0703 \mathrm{~g})$ & $80 \mu \mathrm{g}$ & $0.0124 \%$ \\
\hline Volume of the adsorbent $U\left(V_{\mathrm{CP}}\right)\left(V_{\mathrm{CP}} \approx 0.6462 \mathrm{~cm}^{3}\right)$ & $0.0090 \mathrm{~cm}^{3}$ & $0.1504 \%$ \\
\hline Density of condensed fluid $U\left(\rho_{\text {sorp }}\right) / \rho_{\text {sorp }}{ }^{\mathrm{c}}$ & $10 \%$ & $0.9155 \%$ \\
\hline Mass of zeolite sample $m_{\mathrm{P}}(2.1549 \mathrm{~g})$ & $0.0431 \mathrm{~g}$ & $2.0001 \%$ \\
\hline \multicolumn{2}{|l|}{ Relative combined expanded uncertainty $(k=2)$ in adsorption capacity ${ }^{\mathrm{d}} U_{\mathrm{C}}\left(q_{\mathrm{P}}\right) / q_{\mathrm{P}}$} & $2.2053 \%$ \\
\hline
\end{tabular}

As an example, the measurement at $\left(T=283.165 \mathrm{~K}, p=3.9881 \mathrm{MPa}, \rho=107.851 \mathrm{~kg} \cdot \mathrm{m}^{-3}\right)$ of carbon dioxide was taken (see Table 3)

Adsorbed mass on the zeolite sample $m_{\text {sorp }} \approx(0.7107 \pm 0.0066 \mathrm{~g}) ; m_{\text {sorp }} / m_{\mathrm{P}} \approx 0.3298 \mathrm{~g} / \mathrm{g}$


fore, they are not listed in the table

${ }^{\mathrm{b}}$ Combined uncertainty according to Eq. (6), which includes the uncertainty in temperature and pressure measurement, and the uncertainty of the density calcuated with the reference equation of Span and Wagner (1996) for carbon dioxide

${ }^{\mathrm{c}} \rho_{\text {sorp }} \approx 1178 \mathrm{~kg} \cdot \mathrm{m}^{-3}$. The assumption of the density $\rho_{\text {sorp }}$ is explained in Sect. 4.2. Its uncertainty was estimated to be $10 \%$, however, it could be much larger; see discussion in Sect. 4.2

${ }^{\mathrm{d}}$ Calcuated with Eq. (14)

methane on shale, or hydrogen on metal-organic frameworks) were under investigation, the improvement could be beneficial. Furthermore, for the purpose of accurate determination of the adsorption on non-porous material (e.g., the solid sinker with rough surface in this work), the improvement was significant as discussed in the next section.

\section{Sorption measurements on a solid sinker}

\subsection{Measurement and results}

Test measurements of the adsorption of carbon dioxide on the surface of the sorption sinker was conducted along the isotherm $T=283.175 \mathrm{~K}$, using the improved measurement system as a tandem-sinker densimeter. Measurements were carried out with pressure-increasing steps from $p=2 \mathrm{MPa}$ up to the dew-point pressure and then with pressuredecreasing steps. 
Table 5 Adsorption $q_{\mathrm{NP}}$ of carbon dioxide on the surface of the density sinker and the sorption sinker along the isotherm $T=283.175 \mathrm{~K}$, where $T$ is the temperature (ITS-90), $p$ is the pressure, and $U_{\mathrm{C}}\left(q_{\mathrm{NP}}\right)$ is the expanded combined uncertainty $(k=2)$ of $q_{\mathrm{NP}}$

\begin{tabular}{|c|c|c|c|c|c|c|c|c|c|c|}
\hline \multirow[b]{2}{*}{$T / \mathrm{K}$} & \multirow[b]{2}{*}{$p / \mathrm{MPa}$} & \multirow[b]{2}{*}{$\begin{array}{l}\rho_{\mathrm{EOS}}{ }^{\prime} \\
\mathrm{kg} \cdot \mathrm{m}^{-3}\end{array}$} & \multicolumn{4}{|c|}{ Sorption sinker } & \multicolumn{4}{|c|}{ Density sinker } \\
\hline & & & $\begin{array}{l}\rho_{\exp } / \\
\mathrm{kg} \cdot \mathrm{m}^{-3}\end{array}$ & $100 \cdot \Delta \rho / \rho$ & $\begin{array}{l}q_{\mathrm{NP}} / \\
\mathrm{mmol} \cdot \mathrm{m}^{-2}\end{array}$ & $\begin{array}{l}U_{\mathrm{C}}\left(q_{\mathrm{NP}}\right) / \\
\mathrm{mmol} \cdot \mathrm{m}^{-2}\end{array}$ & $\begin{array}{l}\rho_{\exp } / \\
\mathrm{kg} \cdot \mathrm{m}^{-3}\end{array}$ & $100 \cdot \Delta \rho / \rho$ & $\begin{array}{l}q_{\mathrm{NP}} / \\
\mathrm{mmol} \cdot \mathrm{m}^{-2}\end{array}$ & $\begin{array}{l}U_{\mathrm{C}}\left(q_{\mathrm{NP}}\right) / \\
\mathrm{mmol} \cdot \mathrm{m}^{-2}\end{array}$ \\
\hline 283.178 & 2.0081 & 43.1937 & 43.1915 & -0.005 & 0.008 & 0.232 & 43.1949 & 0.003 & -0.075 & 1.463 \\
\hline 283.196 & 2.4943 & 56.0370 & 56.0417 & 0.008 & -0.015 & 0.239 & 56.0365 & -0.001 & 0.013 & 1.645 \\
\hline 283.204 & 2.9900 & 70.6669 & 70.6714 & 0.006 & -0.018 & 0.249 & 70.6648 & -0.003 & 0.126 & 1.897 \\
\hline 283.206 & 3.4935 & 87.7322 & 87.7398 & 0.009 & -0.033 & 0.263 & 87.7274 & -0.005 & 0.301 & 2.263 \\
\hline 283.208 & 3.9857 & 107.685 & 107.686 & 0.001 & -0.025 & 0.286 & 107.674 & -0.010 & 0.640 & 2.827 \\
\hline 283.210 & 4.1936 & 117.603 & 117.601 & -0.002 & -0.028 & 0.300 & 117.589 & -0.012 & 0.816 & 3.192 \\
\hline 283.207 & 4.3909 & 128.269 & 128.254 & -0.012 & 0.005 & 0.321 & 128.245 & -0.019 & 1.607 & 3.685 \\
\hline 283.197 & 4.4528 & 131.965 & 131.923 & -0.032 & 0.084 & 0.329 & 131.937 & -0.021 & 1.707 & 3.890 \\
\hline 283.190 & 4.4667 & 132.830 & 132.792 & -0.028 & 0.069 & 0.331 & 132.801 & -0.022 & 1.883 & 3.941 \\
\hline 283.178 & 4.4776 & 133.538 & 133.472 & -0.050 & 0.166 & 0.333 & 133.507 & -0.024 & 1.971 & 3.984 \\
\hline 283.180 & 4.4880 & 134.180 & 134.066 & -0.085 & 0.334 & 0.335 & 134.147 & -0.025 & 2.109 & 4.023 \\
\hline 283.186 & 4.4976 & 134.775 & 134.502 & -0.202 & 0.899 & 0.337 & 134.737 & -0.028 & 2.435 & 4.060 \\
\hline 283.183 & $4.5033^{\mathrm{a}}$ & 135.141 & 134.266 & -0.648 & 3.039 & 0.343 & 135.087 & -0.039 & 3.415 & 4.084 \\
\hline 283.182 & 4.4945 & 134.589 & 134.385 & -0.151 & 0.657 & 0.336 & 134.558 & -0.023 & 2.084 & 4.049 \\
\hline 283.179 & 4.4844 & 133.960 & 133.871 & -0.066 & 0.250 & 0.334 & 133.933 & -0.020 & 1.770 & 4.010 \\
\hline 283.178 & 4.4748 & 133.365 & 133.304 & -0.046 & 0.150 & 0.333 & 133.337 & -0.021 & 1.808 & 3.974 \\
\hline 283.174 & 4.4231 & 130.233 & 130.203 & -0.023 & 0.048 & 0.325 & 130.211 & -0.016 & 1.393 & 3.793 \\
\hline 283.161 & 4.2488 & 120.534 & 120.519 & -0.013 & 0.013 & 0.306 & 120.522 & -0.010 & 0.690 & 3.317 \\
\hline 283.162 & 4.0450 & 110.467 & 110.458 & -0.008 & 0.003 & 0.290 & 110.463 & -0.004 & 0.226 & 2.923 \\
\hline 283.150 & 3.5420 & 89.5769 & 89.5709 & -0.007 & 0.010 & 0.265 & 89.5786 & 0.002 & -0.138 & 2.308 \\
\hline 283.153 & 3.0230 & 71.7367 & 71.7325 & -0.006 & 0.010 & 0.250 & 71.7387 & 0.003 & -0.126 & 1.918 \\
\hline 283.156 & 2.5102 & 56.4965 & 56.4891 & -0.013 & 0.023 & 0.239 & 56.4976 & 0.002 & -0.088 & 1.652 \\
\hline 283.156 & 2.0125 & 43.3093 & 43.2955 & -0.032 & 0.046 & 0.232 & 43.3100 & 0.002 & -0.050 & 1.465 \\
\hline
\end{tabular}

The density $\rho_{\mathrm{EOS}}$ was calculated with the reference equation of state (Span and Wagner 1996), $\rho_{\exp }$ is the experimental density, and $\Delta \rho / \rho=\left(\rho_{\exp }-\rho_{\mathrm{EOS}}\right) / \rho_{\mathrm{EOS}}$ is the relative deviation of the experimental density from the calculated density

The expanded uncertainties $(k=2)$ of the measurements are $16 \mathrm{mK}$ for temperature $T$ and between $(0.1$ and 0.7$) \mathrm{kPa}$ for pressure $p$

${ }^{\text {a }}$ The dew-point pressure of carbon dioxide at $T=283.183 \mathrm{~K}$ is $p_{\mathrm{s}} \approx 4.5059 \mathrm{MPa}$

Assuming that there is no adsorption on both the density sinker and the sorption sinker, the measured densities using both sinkers are listed in Table 5. When the density was calculated using the sorption sinker, an equation analogous to Eq. (5) was used with $m^{*}{ }_{\mathrm{S} \text {,vac }}$ replaced by $m_{\mathrm{CP} \text {,vac }}, m_{\mathrm{S} \text {,fluid }}$ replaced by $m^{*}{ }_{\mathrm{CP}, \text { fluid }}$, and furthermore, with the volume $V_{\mathrm{S}}$ and the density $\rho_{\mathrm{S}}$ of the sorption sinker, and the values $\varepsilon_{\mathrm{vac}, 01}$ and $\varepsilon_{\rho, 01}$ for the change in height of the permanent magnet between the positions ZP and MP1. Relative deviations of the experimental densities of carbon dioxide from values calculated with the reference EOS (Span and Wagner 1996) are illustrated in Fig. 5a, b. As shown in these figures, the measured densities agree with the reference EOS within mutual uncertainties at pressures lower than $0.85 \cdot p_{\mathrm{s}}$. However, when the dew point is approached, the measured densities, especially those calculated with the sorption sinker, are distorted, which implies a significant impact from surface phenomena (e.g., adsorption and capillary condensation).
The trend of the deviation of the experimental values in Fig. 5a, b for the sorption sinker qualitatively agree with the theoretical calculation results of Philip (1978), in analyzing combined adsorption and capillary condensation on rough surfaces (see Fig. 8 in Philip 1978), and with the results of Herminghaus (2012), in calculating the adsorption isotherms on surfaces with Gaussian roughness (see Fig. 3 in Herminghaus 2012).

When adsorption (and capillary condensation) of the sample gas on the sinker surface was taken into consideration, the adsorption capacity $q_{\mathrm{NP}}$ (see Eq. (12)) of both sinkers for carbon dioxide are listed in Table 5 and illustrated in Fig. 5c, d; please note that the density of carbon dioxide was calculated with a reference EOS (Span and Wagner 1996). When the adsorbed mass on the surface of the density sinker was calculated, an equation analogous to Eq. (10) was used with $m_{\mathrm{CP} \text {,fluid }}$ replaced by $m_{\mathrm{S} \text {,fluid, }}{ }^{*}$ $m_{\mathrm{CP}, \text { vac }}^{*}$ replaced by $m_{\mathrm{S}, \mathrm{vac}}$, and furthermore, with the 
Table 6 Uncertainty budget for the adsorption capacity $q_{\mathrm{NP}}$ for carbon dioxide on surface of the sorption sinker and density sinker (see Eq. (16))

\begin{tabular}{|c|c|c|c|}
\hline \multirow[b]{2}{*}{ Source $^{\mathrm{a}}$} & \multirow[t]{2}{*}{$\begin{array}{l}\text { Uncertainty } U \\
(k=2)\end{array}$} & \multicolumn{2}{|c|}{$\begin{array}{l}\text { Contribution to } U_{\mathrm{C}}\left(q_{\mathrm{NP}}\right) /\left(\mathrm{mmol} \cdot \mathrm{m}^{-2}\right) \\
(k=2)\end{array}$} \\
\hline & & Sorption sinker & Density sinker \\
\hline \multicolumn{4}{|l|}{ Our improved gravimetric sorption analyzer } \\
\hline Temperature $T$ & $16 \mathrm{mK}$ & $(0.070)$ & $(1.28)$ \\
\hline Pressure $p$ & $0.2 \mathrm{kPa}$ & $(0.060)$ & $(1.09)$ \\
\hline Density calculated with equation of Span and Wagner (1996) & $0.03 \%$ & $(0.107)$ & $(1.95)$ \\
\hline Combined uncertainty in density $U_{\mathrm{C}}(\rho)^{\mathrm{b}}$ & $0.043 \mathrm{~kg} \cdot \mathrm{m}^{-3}$ & 0.141 & 2.57 \\
\hline Weighing value $m_{\mathrm{CP} \text {,vac }}^{*}(9.3386 \mathrm{~g}), m_{\mathrm{S} \text {,vac }}^{*}(19.6571 \mathrm{~g})$ & $60 \mu \mathrm{g}$ & 0.168 & 0.83 \\
\hline Weighing value $m_{\mathrm{CP} \text {,fluid }}(9.2117 \mathrm{~g}), m_{\mathrm{S} \text {,fluid }}^{*}(19.1868 \mathrm{~g})$ & $60 \mu \mathrm{g}$ & 0.168 & 0.83 \\
\hline Volume of the sorption sinker and the density sinker $V_{\mathrm{CP}} \| V_{\mathrm{S}}$ & $0.001 \% \| 0.02 \%$ & 0.071 & 0.07 \\
\hline Combined expanded uncertainty $(k=2)$ in adsorption capacity ${ }^{\mathrm{c}} U_{\mathrm{C}}\left(q_{\mathrm{NP}}\right)$ & 0.286 & & 2.83 \\
\hline \multicolumn{4}{|l|}{ A typical commercial gravimetric sorption analyzer } \\
\hline Temperature $T$ & $300 \mathrm{mK}$ & $(1.319)$ & $(24.03)$ \\
\hline Pressure $p$ & $3.5 \mathrm{kPa}$ & $(0.522)$ & $(9.51)$ \\
\hline Density calculated with equation of Span and Wagner (1996) & $0.03 \%$ & $(0.107)$ & $(1.95)$ \\
\hline Combined uncertainty in density $U_{\mathrm{C}}(\rho)^{\mathrm{b}}$ & $0.055 \mathrm{~kg} \cdot \mathrm{m}^{-3}$ & 1.423 & 25.92 \\
\hline Weighing value $m_{\mathrm{CP}, \text { vac }}^{*}(9.3386 \mathrm{~g}), m_{\mathrm{S} \text {,vac }}^{*}(19.6571 \mathrm{~g})$ & $80 \mu \mathrm{g}$ & 0.224 & 1.11 \\
\hline Weighing value $m_{\mathrm{CP} \text {,fluid }}^{*}(9.2117 \mathrm{~g}), m_{\mathrm{S} \text {,fluid }}^{*}(19.1868 \mathrm{~g})$ & $80 \mu \mathrm{g}$ & 0.224 & 1.11 \\
\hline Volume of the sorption sinker and the density sinker $V_{\mathrm{CP}} \| V_{\mathrm{S}}$ & $0.05 \% \| 0.05 \%$ & 0.178 & 3.24 \\
\hline Combined expanded uncertainty $(k=2)$ in adsorption capacity ${ }^{\mathrm{c}} U_{\mathrm{C}}\left(q_{\mathrm{NP}}\right)$ & 1.468 & & 26.17 \\
\hline
\end{tabular}

As an example, the measurement at $\left(T=283.208 \mathrm{~K}, p=3.9857 \mathrm{MPa}, \rho=107.685 \mathrm{~kg} \cdot \mathrm{m}^{-3}\right)$ of carbon dioxide was taken (see Table 5)

The measured adsorption capacity was significantly smaller than the uncertainty at almost all pressures (see Table 5)

${ }^{\mathrm{a}}$ The influence of the uncertainties of the FTE correction factors $\varepsilon_{\text {vac }}$ and $\varepsilon_{\text {fluid }}$ for the two sinkers, the density of the condensed fluid $\rho_{\text {sorb }}$, and the geometrical surface area $A$ to the uncertainty of $q_{\mathrm{NP}}$ is relatively small and can be neglected; see Sect. 3.4

${ }^{\mathrm{b}}$ Combined uncertainty according to Eq. (6), which includes the uncertianty in temperature and pressure measurement, and the uncertainty of the density calcuated with the reference equation of Span and Wagner (1996) for carbon dioxide

${ }^{\mathrm{c}}$ Calcuated with Eq. (16)

volume $V_{\mathrm{S}}$ and the density $\rho_{\mathrm{S}}$ of the density sinker, and the values $\varepsilon_{\text {vac,12 }}$ and $\varepsilon_{\text {fluid,12 }}$ for the change in height of the permanent magnet between the positions MP1 and MP2. As can be seen in Fig. 5c, d and listed in Table 5, the adsorption capacity $q_{\mathrm{NP}}$ of the density sinker at all measuring points are not reliable because the value is smaller than its uncertainty (see Sect. 5.2). In contrast to that, the adsorption capacity $q_{\mathrm{NP}}$ on the surface of the sorption sinker in the vicinity of the dew point $\left(p>0.995 \cdot p_{\mathrm{s}}\right)$ is reliable (the value is larger than its uncertainty) with values up to $q_{\mathrm{NP}}=3.0 \mathrm{mmol} \cdot \mathrm{m}^{-2}$. This result implies that in the vicinity of the dew point $\left(p>0.995 \cdot p_{\mathrm{s}}\right)$, capillary condensation dominates the surface interaction between the sample fluid and the solid surfaces, and the adsorption capacity can be measured by our improved measurement system. Further studies on surface phenomena in the vicinity of the dew point of pure fluids and fluid mixtures, using sinkers with different surface characteristics (e.g., with gold plated surfaces), are presented by Yang and Richter (2020).

\subsection{Uncertainty analysis}

For our improved measurement system, the combined uncertainty in density of the sample fluid was calculated by Eq. (6), with the expanded uncertainties $(k=2)$ in temperature, pressure and density being $16 \mathrm{mK},(0.2$ to 0.7$)$ $\mathrm{kPa}$ and $0.03 \%$ (Span and Wagner 1996), respectively. The expanded uncertainty $(k=2)$ of the weighing values $m^{*}{ }_{\mathrm{CP}, \text { fluid }}$ and $m^{*}{ }_{\mathrm{CP}, \text { vac }}$ were both estimated to be $60 \mu \mathrm{g}$. The relative expanded uncertainties $(k=2)$ of the volume of the sinkers were obtained from the volume calibration (see Table 1), i.e., $U\left(V_{\mathrm{S}}\right) / V_{\mathrm{S}}=0.001 \%$ for the density sinker and $U\left(V_{\mathrm{CP}}\right) / V_{\mathrm{CP}}=0.02 \%$ for the sorption sinker. The combined uncertainty in sorption capacity $q_{\mathrm{NP}}$ was then calculated with Eq. (16). If the FTE was not taken into consideration, see Eq. (10) and the following comments, the error of $m_{\text {sorp }}$ would be in the order of $0.3 \mathrm{mg}$ for the current case, 
which corresponds to $0.7 \mathrm{mmol} \cdot \mathrm{m}^{-2}$ or about $22 \%$ of the adsorption capacity $q_{\mathrm{NP}}$ for the $(p, T)$ state with the highest adsorption, i.e., for the present measurements, near the dew-point pressure (see Table 5). Hence, for a nonporous material, the influence of the FTE has to be taken into account.

The uncertainty budget for the adsorption capacity $q_{\mathrm{NP}}$ of both sinkers for carbon dioxide, measured with our improved measurement system, is summarized in Table 6, with the measurement at $T=283.208 \mathrm{~K}$ and $p=3.9857 \mathrm{MPa}$ as an example. Each of the uncertainty parameters (measurements of temperature, pressure and weighing values; density calculated with reference EOS; volume of the sinkers), which are presented in Table 6 , has a non-negligible influence to the combined uncertainty of the adsorption capacity. Since the uncertainty of the density of the adsorbed fluid $u\left(\rho_{\text {sorp }}\right)$ is not a dominant factor, the excess adsorption and the absolute adsorption for nonporous materials are almost at the same level of uncertainty. As can be seen in Table 6, the uncertainty in adsorption capacity $q_{\mathrm{NP}}$ of the density sinker is much larger than that of the sorption sinker. The main reason is that the surface-to-volume ratio of the sorption sinker is approximately 18.2 times greater than that of the density sinker. Therefore, the contribution of the combined uncertainty in density for the density sinker was approximately 18.2 times greater than that for the sorption sinker, as can be derived from Eqs. (12) and (16). The combined expanded uncertainty $(k=2)$ of the adsorption capacity $q_{\mathrm{NP}}$ for each measuring point are listed in Table 5. The values of the adsorption capacity of the density sinker at all measuring points are smaller than their expanded uncertainty, while the values of the adsorption capacity of the sorption sinker are larger in the vicinity of the dew point $\left(p>0.995 \cdot p_{\mathrm{s}}\right)$. Therefore, our improved measurement system was accurate enough for the investigation of the adsorption on the sorption sinker, but not for the density sinker.

In Table 6, the uncertainty budget of a typical commercial gravimetric sorption analyzer is also listed. As in Sect. 4.2, the expanded uncertainties $(k=2)$ in the measurements of temperature, pressure, and weighing values were estimated to be $300 \mathrm{mK}, 3.5 \mathrm{kPa}$, and $80 \mu \mathrm{g}$, respectively. The relative expanded uncertainties $(k=2)$ of the volume of the density sinker were obtained from a volume calibration certificate provided by the manufacturer (Rubotherm), i.e., $U\left(V_{\mathrm{S}}\right) /$ $V_{\mathrm{S}}=0.05 \%$ and we assume the same uncertainty for the sorption sinker $U\left(V_{\mathrm{CP}}\right) / V_{\mathrm{CP}}=0.05 \%$. As can be seen in Table 6 , the uncertainty in the adsorption capacity $U_{\mathrm{C}}\left(q_{\mathrm{NP}}\right)$ of the sinkers using a typical commercial gravimetric sorption analyzer is much larger than that of our improved measurement system. The uncertainty is larger than the sorption capacity $q_{\mathrm{NP}}$ itself at all measuring points for both sinkers. Therefore, a typical commercial gravimetric sorption analyzer is not accurate enough to measure the adsorption on the surface of a quasi non-porous material significantly better than its uncertainty.

\section{Conclusion}

For the determination of the adsorption of gases on porous and quasi non-porous materials, the technique of a commercial gravimetric sorption analyzer was investigated, and a detailed uncertainty analysis was presented. The uncertainty analysis was applied to both a typical commercial apparatus and a measurement system improved by us. The force-transmission error (FTE) of the magnetic-suspension coupling was also taken into account.

As a representative of porous material, Zeolite 13X was used, and the test measurements were conducted with carbon dioxide along the isotherm $T=283.144 \mathrm{~K}$ from $p=0.0001 \mathrm{MPa}$ up to the dew-point pressure. The measurement results agree with reliable literature data. The uncertainty of the adsorption capacity of the porous material is largely attributed to the porous sample itself (mass and volume of the sample) rather than the measurement technique with a gravimetric sorption analyzer. The influence of the FTE on the uncertainty of the adsorbed mass on porous material was negligibly small.

Adsorption measurements were also carried out with carbon dioxide on solid sinkers (quasi non-porous material) along the isotherm $T=283.175 \mathrm{~K}$ from $p=2 \mathrm{MPa}$ up to the dew-point pressure. Two sinkers were investigated: a density sinker with a relatively small surface-to-volume ratio and a smooth surface, and a sorption sinker with a relatively large surface-to-volume ratio and a rough surface. The most important uncertainty contributions in the adsorption measurement on a non-porous material are the weighing values of the balance, the density of the investigated fluid in the gas phase, and the volume of the non-porous material. The uncertainty analysis demonstrated that our improved measurement system was able to measure the condensed mass of the sample gas on the surface of the sorption sinker in the vicinity of the dew point (capillary condensation), while the accuracy of a typical commercial apparatus was clearly not sufficient. In case of a quasi non-porous material, the influence of the FTE had a significant impact.

Acknowledgements Open Access funding provided by Projekt DEAL. The authors are grateful to Deutsche Forschungsgemeinschaft (DFG) for funding their on-going research on new approaches for measurement and modelling of fluid mixture dew-point densities within the Emmy Noether Programme under Grant No. RI 2482/2-1. 
Open Access This article is licensed under a Creative Commons Attribution 4.0 International License, which permits use, sharing, adaptation, distribution and reproduction in any medium or format, as long as you give appropriate credit to the original author(s) and the source, provide a link to the Creative Commons licence, and indicate if changes were made. The images or other third party material in this article are included in the article's Creative Commons licence, unless indicated otherwise in a credit line to the material. If material is not included in the article's Creative Commons licence and your intended use is not permitted by statutory regulation or exceeds the permitted use, you will need to obtain permission directly from the copyright holder. To view a copy of this licence, visit http://creativecommons.org/licenses/by/4.0/.

\section{References}

Arami-Niya, A., Rufford, T.E., Dresp, G., Al Ghafri, S., Jiao, F., May, E.F.: Measurements of helium adsorption on natural clinoptilolite at temperatures from (123.15 to 423.15$) \mathrm{K}$ and pressures up to 35 MPa. Sep. Purif. Technol. 223, 1-9 (2019)

Brandani, S., Mangano, E., Sarkisov, L.: Net, excess and absolute adsorption and adsorption of helium. Adsorption 22, 261-276 (2016)

Broom, D.P., Webb, C.J.: Pitfalls in the characterisation of the hydrogen sorption properties of materials. Int. J. Hydrog. Energy 42, 29320-29343 (2017)

Brunauer, S., Deming, L.S., Deming, W.E., Teller, E.: On a theory of the van der Waals adsorption of gases. J. Am. Chem. Soc. 62 , 1723-1732 (1940)

Cavenati, S., Grande, C.A., Rodrigues, A.E.: Adsorption equilibrium of methane, carbon dioxide, and nitrogen on zeolite $13 \mathrm{X}$ at high pressures. J. Chem. Eng. Data 49, 1095-1101 (2004)

Deng, H., Yi, H., Tang, X., Yu, Q., Ning, P., Yang, L.: Adsorption equilibrium for sulfur dioxide, nitric oxide, carbon dioxide, nitrogen on 13X and 5A zeolites. Chem. Eng. J. 188, 77-85 (2012)

Dreisbach, F., Lösch, H.W.: Magnetic suspension balance for simultaneous measurement of a sample and the density of the measuring fluid. J. Therm. Anal. Calorim. 62, 515-521 (2000)

Dreisbach, F., Staudt, R., Keller, J.U.: High pressure adsorption data of methane, nitrogen, carbon dioxide and their binary and ternary mixtures on activated carbon. Adsorption 5, 215-227 (1999)

Gensterblum, Y., Van Hemert, P., Billemont, P., Busch, A., Charriere, D., Li, D., Krooss, B.M., De Weireld, G., Prinz, D., Wolf, K.-H.: European inter-laboratory comparison of high pressure $\mathrm{CO} 2$ sorption isotherms: I: Activated carbon. Carbon 47, 2958-2969 (2009)

Hefti, M., Marx, D., Joss, L., Mazzotti, M.: Adsorption equilibrium of binary mixtures of carbon dioxide and nitrogen on zeolites ZSM-5 and 13X. Microporous Mesoporous Mater. 215, 215-228 (2015)

Herminghaus, S.: Wetting, spreading, and adsorption on randomly rough surfaces. Eur. Phys. J. E 35, 43 (2012)

Hocker, T., Rajendran, A., Mazzotti, M.: Measuring and modeling supercritical adsorption in porous solids: carbon dioxide on $13 \mathrm{X}$ zeolite and on silica gel. Langmuir 19, 1254-1267 (2003)

Hyun, S.H., Danner, R.P.: Equilibrium adsorption of ethane, ethylene, isobutane, carbon dioxide, and their binary mixtures on $13 \mathrm{X}$ molecular sieves. J. Chem. Eng. Data 27, 196-200 (1982)

ISO/IEC Guide 98-3: Uncertainty of measurement - Part 3: guide to the expression of uncertainty in measurement (GUM:1995). International Organization for Standardization, Geneva (2008)
Kaye, S.S., Dailly, A., Yaghi, O.M., Long, J.R.: Impact of preparation and handling on the hydrogen storage properties of $\mathrm{Zn}_{4} \mathrm{O}$ (1, 4-benzenedicarboxylate) ${ }_{3}$ (MOF-5). J. Am. Chem. Soc. 129, 14176-14177 (2007)

Kleinrahm, R., Yang, X., McLinden, M., Richter, M.: Analysis of the systematic force-transmission error of the magnetic-suspension coupling in single-sinker densimeters and commercial gravimetric sorption analyzers. Adsorption 25, 717-735 (2019)

Maggs, F., Schwabe, P., Williams, J.: Adsorption of helium on carbons: influence on measurement of density. Nature 186, 956 (1960)

Malbrunot, P., Vidal, D., Vermesse, J., Chahine, R., Bose, T.: Adsorbent helium density measurement and its effect on adsorption isotherms at high pressure. Langmuir 13, 539-544 (1997)

May, E.F., Miller, R.C., Shan, Z.: Densities and dew points of vapor mixtures of (methane + propane) and (methane + propane + hexane) using a dual-sinker densimeter. J. Chem. Eng. Data 46, 1160-1166 (2001)

McLinden, M.O., Kleinrahm, R., Wagner, W.: Force transmission errors in magnetic suspension densimeters. Int. J. Thermophys. 28, 429-448 (2007)

Nguyen, H.G.T., Espinal, L., van Zee, R.D., Thommes, M., Toman, B., Hudson, M.S.L., Mangano, E., Brandani, S., Broom, D.P., Benham, M.J.: A reference high-pressure $\mathrm{CO}_{2}$ adsorption isotherm for ammonium ZSM-5 zeolite: results of an interlaboratory study. Adsorption 24, 531-539 (2018)

Ortiz Vega, D.O.: A new wide range equation of state for helium-4. Dissertation, Texas A\&M University. (2013).

Ottiger, S., Pini, R., Storti, G., Mazzotti, M.: Competitive adsorption equilibria of $\mathrm{CO}_{2}$ and $\mathrm{CH}_{4}$ on a dry coal. Adsorption 14, 539-556 (2008)

Philip, J.R.: Adsorption and capillary condensation on rough surfaces. J. Phys. Chem. 82, 1379-1385 (1978)

Pini, R.: Interpretation of net and excess adsorption isotherms in microporous adsorbents. Microporous Mesoporous Mater. 187, 40-52 (2014)

Sips, R.: On the structure of a catalyst surface. J. Chem. Phys. 16, 490-495 (1948)

Span, R., Wagner, W.: A new equation of state for carbon dioxide covering the fluid region from the triple point temperature to $1100 \mathrm{~K}$ at pressures up to $800 \mathrm{MPa}$. J. Phys. Chem. Ref. Data 25, 1509-1596 (1996)

Toth, J.: State equations of the solid-gas interface layers. Acta Chim. Acad. Sci. Hung. 69, 311-328 (1971)

Wang, Y., LeVan, M.D.: Adsorption equilibrium of carbon dioxide and water vapor on zeolites $5 \mathrm{~A}$ and $13 \mathrm{X}$ and silica gel: pure components. J. Chem. Eng. Data 54, 2839-2844 (2009)

Yang, X., Richter, M.: Experimental investigation of surface phenomena on quasi nonporous and porous materials near dew points of pure fluids and their mixtures. Ind. Eng. Chem. Res. 59, 3238$3251(2020)$

Zlotea, C., Moretto, P., Steriotis, T.: A Round Robin characterisation of the hydrogen sorption properties of a carbon based material. Int. J. Hydrog. Energy 34, 3044-3057 (2009)

Publisher's Note Springer Nature remains neutral with regard to jurisdictional claims in published maps and institutional affiliations. 